\title{
High-resolution 3D analyses of the shape and internal constituents of small volcanic ash particles: The contribution of SEM micro-computed tomography (SEM micro-CT)
}

\author{
Pierre Vonlanthen ${ }^{\mathrm{a}, *}$, Juanita Rausch ${ }^{\mathrm{b}}$, Richard A. Ketcham ${ }^{\mathrm{c}}$, Benita Putlitz ${ }^{\mathrm{a}}$, \\ Lukas P. Baumgartner ${ }^{\mathrm{a}}$, Bernard Grobéty ${ }^{\mathrm{b}}$ \\ a Institute of Earth Sciences, University of Lausanne, UNIL Mouline, Building Géopolis, CH-1015 Lausanne, Switzerland \\ b Department of Geosciences, University of Fribourg, Chemin du Musée 6, CH-1700 Fribourg, Switzerland \\ ' Department of Geological Sciences, Jackson School of Geosciences, University of Texas at Austin, 1 University Station C1100, Austin, TX 78712, USA
}

\begin{abstract}
The morphology of small volcanic ash particles is fundamental to our understanding of magma fragmentation, and in transport modeling of volcanic plumes and clouds. Until recently, the analysis of 3D features in small objects $(<250 \mu \mathrm{m})$ was either restricted to extrapolations from 2D approaches, partial stereo-imaging, or CT methods having limited spatial resolution and/or accessibility. In this study, an X-ray computed-tomography technique known as SEM micro-CT, also called 3D X-ray ultramicroscopy (3D XuM), was used to investigate the 3D morphology of small volcanic ash particles (125-250 $\mu \mathrm{m}$ sieve fraction), as well as their vesicle and microcrystal distribution. The samples were selected from four stratigraphically well-established tephra layers of the Meerfelder Maar (West Eifel Volcanic Field, Germany). Resolution tests performed on a Beametr v1 pattern sample along with Monte Carlo simulations of X-ray emission volumes indicated that a spatial resolution of $0.65 \mu \mathrm{m}$ was obtained for X-ray shadow projections using a standard thermionic SEM and a bulk brass target as X-ray source. Analysis of a smaller volcanic ash particle (64-125 $\mu \mathrm{m}$ sieve fraction) showed that features with volumes $>20 \mu^{3}$ ( $3.5 \mu \mathrm{m}$ in diameter) can be successfully reconstructed and quantified. In addition, new functionalities of the Blob3D software were developed to allow the particle shape factors frequently used as input parameters in ash transport and dispersion models to be calculated. This study indicates that SEM micro-CT is very well suited to quantify the various aspects of shape in fine volcanic ash, and potentially also to investigate the 3D morphology and internal structure of any object $<0.1 \mathrm{~mm}^{3}$.
\end{abstract}

\section{Introduction and previous work}

Volcanic ash particles carry a wealth of information on various processes occurring during volcanic eruptions. Besides providing insight into the fragmentation processes taking place in the volcanic conduit (Heiken, 1972; Zimanowski et al., 1997; Morrissey et al., 2000; Dellino et al., 2012) and the subsequent transport and comminution of pyroclastic materials (Dellino and La Volpe, 1995; Evans et al., 2009; Manga et al., 2011), the external shape of ash particles allows for determining the physical properties of magma and its degree of interaction with water (Wohletz, 1983; Buettner et al., 1999). In addition, the internal constituents of ash particles, namely vesicles and microcrystals, are crucial in our understanding of the degassing and fractionation history of magma. As frozen records of the degassing processes, vesicles preserve information on the extent

\footnotetext{
* Corresponding author. Tel.: +41 2169235 24; fax: +41 216924305.

E-mail address: pierre.vonlanthen@unil.ch (P. Vonlanthen).
}

and style of bubble nucleation and growth, whereas microcrystals, through their number, size and distribution, can be used to estimate crystal nucleation density and growth rate, or to determine the kinetics of fractionation processes.

Shape is of particular interest when considering the aerial behavior of ash. In terms of aerodynamics, shape has a direct impact on the drag forces acting on rising and falling particles (Stringham et al., 1969; Bursik, 1989; Ganser, 1993; Mitchell, 1996; Chhabra et al., 1999; Mele et al., 2011; Dellino et al., 2012), which in turn influence the settling velocity (Wilson and Huang, 1979; Coltelli et al., 2008; Alfano et al., 2011), the atmospheric residence time (Riley et al., 2003), and the transport distance and dispersal of tephra (Sparks et al., 1997; Scollo et al., 2008). The aerial behavior of ash is also indirectly influenced by the surface-to-volume ratio, which affects the propensity of particles to form aggregates, both in dry and wet environments (e.g. Rose, 1977; Varekamp et al., 1984; Gilbert and Lane, 1994; Witham et al., 2005; Delmelle et al., 2007). Irregular particles with large surface-to-volume ratios are likely to be coated by comparatively more charges and hygroscopic compounds per unit mass than their 
spherical equivalents, making them more reactive to nearby particles and prone to mutual adhesion. Aggregation may be further enhanced by other morphological features, such as surface curvature and roughness, which are known to raise significantly the wettability and adsorption capabilities of particles (Pruppacher and Klett, 1997), and to favor their geometrical interlocking (Sorem, 1982).

The morphology of particles also comes into play when considering health hazards (Blong, 1984) such as eye irritation and respiratory ailments, because the bio-reactivity of particles, mainly imputable to the presence of surface radicals (Horwell et al., 2003), increases along with the surface-to-volume ratio (Fubini et al., 1999; Tran et al., 2000; Hetland et al., 2001). Furthermore, the morphology of ash particles is a concern when dealing with aircraft safety (Casadevall, 1994) and infrastructure damage (Blong, 1984), as the abrasive power of ash is a function of angularity (Stachowiak, 2000).

Because of its profound impact on the aerodynamic behavior and the reactivity of ash, the shape of particles is a determinant factor for the modeling of tephra transport and dispersal and thus, risks mitigation strategies. Until recently, ash particles were commonly modeled as spheres (Brazier et al., 1982; Carey and Sigurdsson, 1982; Suzuki, 1983; Armienti et al., 1988; Glaze and Self, 1991; Sparks et al., 1992; Hurst and Turner, 1999; Bonadonna et al., 2005), mainly because of the difficulty of adequately determining particle shape (Folch, 2012). Such an assumption may result in misinterpretations and errors in the description of volcanic plume behavior. Krotkov et al. (1999) have shown that modeling volcanic ash particles as spherical leads satellite spectrometers to systematically underestimate the total mass of volcanic clouds, a point also raised by Wen and Rose (1994). These flaws have been corrected in most of the recent numerical models (e.g. Macedonio et al., 2005; Costa et al., 2006; Barsotti et al., 2008; Schwaiger et al., 2012) through the integration of a particle shape factor (Wilson and Huang, 1979; Ganser, 1993; Dellino et al., 2005) accounting for the non-spherical character of volcanic ash. The result is a significant improvement in the modeling of tephra transport and dispersal, which underlines the need for reliable techniques to fully characterize the shape of volcanic ash particles.

Traditionally, the shape of volcanic ash particles has been measured using 2D approaches (e.g. Eiríksson et al., 1994; Dellino and La Volpe, 1996; Maria and Carey, 2002, 2007; Riley et al., 2003; Shea et al., 2010). These methods, however, provide only incomplete shape descriptors, due to the inherent limitations of $2 \mathrm{D}$ techniques to fully retrieve 3D features (Baker et al., 2012). The issue has been partly overcome through the use of scanning electron microscopy (SEM) stereoimages to generate 3D digital elevation models of ash particles (Ersoy, 2007, 2010; Carter et al., 2009; Mills and Rose, 2010) and vesicular surfaces (Proussevitch et al., 2011; Genareau et al., 2012). SEM stereoimaging, however, allows for the reconstruction of the upper surface of the sample only, whereas the characteristics of the lower surface, inaccessible to the electron beam, have to be interpolated. Other drawbacks of the method include its inability to collect internal information, such as vesicle and crystal distribution, which influences the density of the particles. These shortcomings can be efficiently circumvented using $\mathrm{X}$-ray micro-computed tomography (X-ray micro-CT) methods. Conventional X-ray micro-CT analyses have been carried out recurrently to investigate volcanic rocks (e.g. Proussevitch et al., 1998; Degruyter et al., 2010), but the limited spatial resolution to $\sim 6 \mu \mathrm{m}$ in X-ray shadow projections of many systems (Jerram and Higgins, 2007) makes those instruments poorly suited for smaller objects such as volcanic ash particles (s. Fig. 4 in Ersoy et al., 2010). Synchrotron X-ray micro-CT is also positively rated in the study of volcanic rocks (Song et al., 2001; Shin et al., 2005) and lapilli-sized pumice and scoria clasts (Gualda and Rivers, 2006; Polacci et al., 2006; Zandomeneghi et al., 2010; Voltolini et al., 2011), as it provides highly coherent monochromatic radiation along with standard micrometer resolution improving down to sub$100 \mathrm{~nm}$ when coupled with a full-field X-ray microscope (Rau et al., 2007). However, it can be difficult to obtain time at such facilities, and may entail long waits, thus highlighting the need for more accessible alternatives.

The first attempt to perform computerized-tomographic X-ray analyses in an SEM dates back to the 80 (Sasov, 1985), but at that time the method was very hard to implement because of limited computer performance and X-ray detection efficiency. Cazaux et al. (1993) later developed a custom-built SEM CT system taking advantage of the availability of charge-coupled devices (CCD) for the acquisition of X-rays. In spite of promising performance, however, the technique received little attention for another decade. A decisive step forward was made by the Commonwealth Scientific and Industrial Research Organisation (CSIRO) group in Australia through the development of X-ray phasecontrast imaging (Wilkins et al., 1996; Mayo et al., 2003). However, it is only with the release of commercial versions of SEM-hosted X-ray attachments and dedicated reconstruction softwares by the Gatan and SkyScan (now Bruker MicroCT) companies in the years 2006-2008 (Brownlow et al., 2006; Sasov, 2008) that this type of analyses has become available for applied research. Since that time the technology has been referred to as SEM micro-CT by Bruker MicroCT and 3D X-ray ultramicroscopy (3D XuM) by Gatan. Regarding volcanology, the imaging capabilities of X-ray microscopes were used by Kiely et al. (2007) on two ash particles erupted from the Hayes and Katmai volcanoes (Alaska) and by Kiely et al. (2011) to investigate the lunar regolith. In both of those studies, however, the X-ray shadow projections (attenuation or phase-contrast images presented as micrographs or rotational movies), were not used for 3D tomographic reconstructions of the samples, thus precluding any quantitative analysis of morphological features.

The present paper, along with the paper of Rausch et al. (2015), reports the first applied study on volcanic ash particles based on full 3D SEM micro-CT analyses. This novel application allows for quantitative 3D morphological analysis of the shape and internal constituents of small objects with potentially sub-micron resolution, which makes it a method of choice for the analysis of volcanic ash. The present contribution focuses on the methodology of SEM micro-CT, with a special attention to the scope and limitations of the technique when applied to volcanic ash, whereas in the paper of Rausch et al. (2015) the morphological data have been used along with fractal analysis to investigate the significance and origin of volatiles in Eifel maar volcanism. Beyond the characterization of ash particles, these two contributions open new perspectives in various fields of Earth and materials sciences for which quantification of 3D features in small objects is required.

\section{Materials}

This study focuses on volcanic ash particles erupted from Meerfelder Maar (MFM), the largest maar volcano in the West Eifel Volcanic Field (Germany). The well-exposed MFM deposits crop out in the Leyendecker quarry, about $400 \mathrm{~m}$ west of the MFM crater rim (s. Appendix 1 in Rausch et al., 2015). The outcrop consists of a 19-23 m thick maar sequence representing the medial to proximal facies of the eruption, as testified by the large volcanic ejecta (blocks up to $1 \mathrm{~m}$ in diameter) present within the deposit.

Volcanic ash particles were sampled in four stratigraphically wellconstrained layers: MFM03, MFM20, MFM40, and MFM45 (s. Table 1 in Rausch et al., 2015). MFM03 is a 6-14 cm thick well-sorted layer made of highly vesicular black scoria lapilli, interpreted as magmatic fallout. Based on light optical microscopy lapilli- to coarse ash-sized juvenile clasts in MFM03 are highly vesicular and glassy (sideromelane) with the morphology dominated by concave particle walls. Layer MFM20 ( $20 \mathrm{~cm}$ in thickness) is a pinkish, moderately to poorly sorted and crudely bedded deposit dominated by lithic fragments (juvenile content: 23 wt.\%). It is interpreted to have been transported and deposited as wet debris jets. Deposits of layer MFM40 (25 cm in thickness) are grayish, bedded and well-sorted (juvenile clast content: $52 \mathrm{wt. \% ),}$ suggesting moderately dry fallout as deposition mechanism. Layer 
MFM45 ( $5 \mathrm{~cm}$ in thickness) is a dark gray, finely bedded and well-sorted deposit (juvenile clast content: 36 wt.\%) interpreted as dry fallout. Juvenile particles from MFM20, MFM40 and MFM45 are typically characterized by round to subround shapes and rugged surface textures. The groundmass is tachylitic (i.e. consisting of a porous mush of imbricate microlites) or glassy and vesicularities range from low to moderate. Microcrystals of olivine, augite and small melilite can be observed in juvenile particles from each of the four studied layers. This mineral assemblage reflects the highly silica-undersaturated and alkali-rich melilite-nephelinitic composition of the erupted MFM magma.

Sixteen ash particles (four from each layer; labeled 1,2,3 and 4, such as e.g. MFM03-1) were selected from the sieve fraction between 125 and $250 \mu \mathrm{m}(2-3 \varphi)$ and analyzed using the SEM micro-CT technique. This sample set enabled us to investigate a wide spectrum of shapes and textures, and to compare morphological features from particles erupted during a single eruptive pulse, and during different stages of the eruption. An additional ash particle (MFM03-5) was collected from the sieve fraction between 64 and $125 \mu \mathrm{m}(3-4 \varphi)$ in order to test the resolving power of the technique and its applicability to finer volcanic ash.

\section{Methods}

\subsection{Principles of conventional vs. SEM micro-CT}

Conventional X-ray micro-CT is a well-established technology first developed for medical purposes (Cormack, 1963; Hounsfield, 1973; New et al., 1974), and subsequently adapted and extended to a wide variety of research fields, including the Earth sciences (Arnold et al., 1983; Conroy and Vannier, 1984; Ketcham and Carlson, 2001). X-ray CT allows for nondestructive 3D visualization and characterization of solids based on differences in the X-ray attenuation coefficients of the sample constituents. The technique is based on the acquisition of X-ray shadow projections of a sample which is step-wise rotated over a wide range of angular orientations. The X-ray shadow projections are used to reconstruct 2D CT slices of the object through a back-projection procedure (s. Natterer and Wübbeling, 2001 for a review on back-projection algorithms). Because blurring is inherent to reconstruction by back-projection, the raw X-ray shadow projections have to be convoluted by high-pass filtering. Slices are then compiled to create a 3D representation of the object, also called volume rendering, which can be manipulated digitally to perform a large array of measurement and visualization tasks. A detailed and upto-date description of the theoretical and technical aspects of conventional X-ray CT techniques can be found in Kalender (2011).

SEM micro-CT allows for tomographic analysis within the chamber of an SEM. Unlike conventional X-ray micro-CT methods, which have a dedicated X-ray source (i.e. a micro-focus X-ray tube or a rotating anode), X-rays used in SEM micro-CT are generated by focusing the electron beam on a metal target placed in the SEM chamber (Fig. 1). Because the acceleration voltage of most SEM guns is limited to $30 \mathrm{kV}$, the energy of the generated X-rays also has a $30 \mathrm{kV}$ upper limit, with a maximum intensity located between $\sim 4$ and $\sim 15 \mathrm{kV}$ (s. Goldstein et al., 2007, pp. 283-284, for a review on overvoltage and the distribution of inner shell ionization energies). Such low-energy X-rays have a small mean free path length, thus restricting the use of SEM micro-CT to small objects, typically $<0.01 \mathrm{~mm}^{3}$, and/or to objects with low $\mathrm{X}$-ray attenuation coefficients. Brass, with critical ionization energies for $\mathrm{K}$ lines ranging between 8.0 and $9.6 \mathrm{kV}$, is the metal target of choice for most SEM micro-CT analyses, especially for objects with intermediate X-ray attenuation coefficients. Brass may be replaced by other metals, such as titanium ( $\mathrm{K}$ lines between 4.5 and $4.9 \mathrm{kV}$ ) to improve the signal-to-noise ratio on $\mathrm{CCD}$ detectors which have better quantum efficiency in the low range of the X-ray spectrum (Pauwels et al., 2010), or gold (L lines between 9.7 and $13.4 \mathrm{kV}$ ), to improve the penetrative power of X-rays through thick objects or those characterized by high attenuation coefficients.
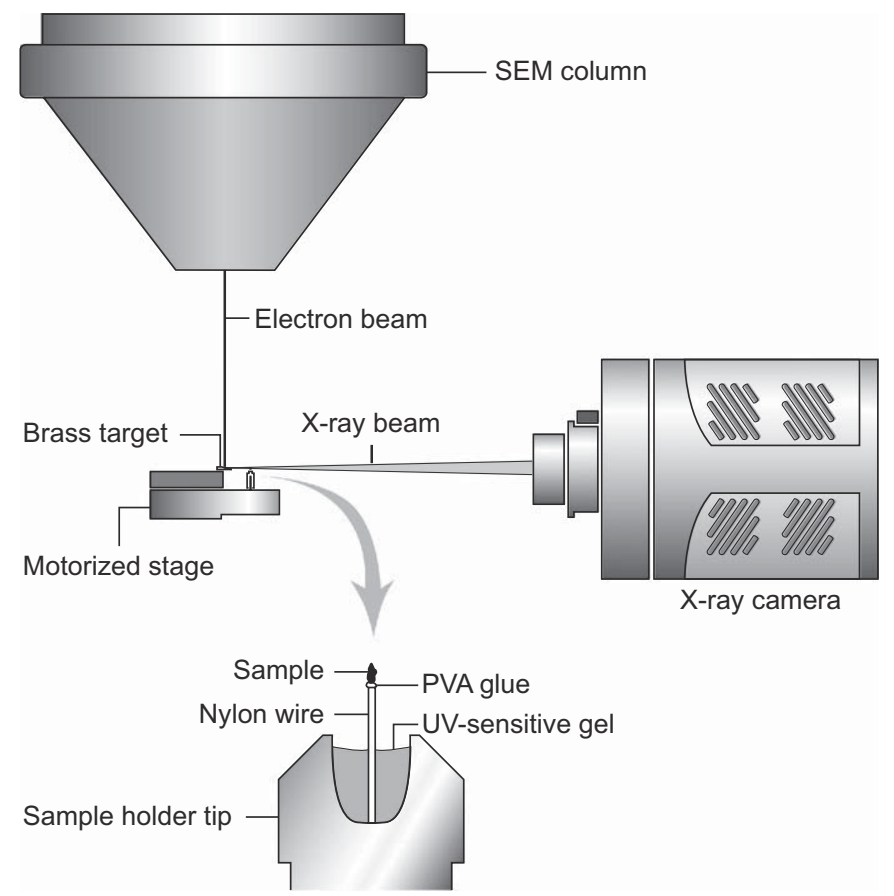

Fig. 1. Schematic illustration of the SEM micro-CT geometry and settings.

SEM micro-CT requires a high probe current intensity (ideally in the hundreds of nA range) to maximize the X-ray flux and thus, to keep the exposure time and the detector gain as low as possible while improving the signal-to-noise ratio in the X-ray shadow projections (Pauwels et al., 2010). In most conventional and field-emission SEMs, however, a high probe current intensity is obtained by increasing the probe diameter, which significantly reduces the spatial resolution. Using such instruments, high-resolution data can be collected only at low probe current intensity, i.e. for a very long acquisition time (>10 h).

\subsection{Sample preparation}

Whereas preparation and mounting of voluminous geological samples for conventional micro-CT techniques are straightforward (Ketcham and Carlson, 2001), the procedure is significantly more challenging for the small samples investigated here with SEM micro-CT. Accurate centering of the particle with respect to the stage rotation axis is of critical importance, as the particle has to stay within the field of view of the X-ray camera during rotation. Off-centered rotation can be partly compensated by an increase of the source-to-sample distance, but with the corresponding decrease in resolution. Because small volcanic ash particles are commonly brittle and therefore, difficult to handle, optimum centering must be reached with minimum manipulation.

The sample holder used in this study consists of a $15 \mathrm{~mm}$ long metallic cylinder with a concave tip, $3.5 \mathrm{~mm}$ in diameter (s. Fig. 1). The concave tip was filled with a drop of UV-sensitive acrylate gel into which a 2 $\mathrm{mm}$ long, $0.25 \mathrm{~mm}$ in diameter nylon wire was inserted. A light microscope equipped with a rotating stage was used to center the nylon wire with respect to the rotation axis of the sample holder while the gel solidified under an UV-lamp. The use of UV-sensitive gel turned out to be more practical than other fixing media due to its better mechanical stability under vacuum. Polyvinyl acetate (PVA) glue was used to fix the volcanic ash particle on top of the nylon wire. The $\mathrm{X}$-ray attenuation coefficient of PVA is very low, which prevents the base of the particle from being shaded during analysis. In addition, PVA glue can be easily removed after micro-CT scanning, enabling further observations of the sample with other methods. The particle is generally 
placed with its long axis in vertical position to allow some flexibility in the centering process.

Sample charging due to interaction with backscatter electrons might occur, but only at high probe current intensity (several hundreds of $n A$ ). If charging problems arise the sample has to be coated by a thin conductive layer. Generally carbon is preferred over gold because gold significantly attenuates X-rays and it complicates the segmentation of the bright (i.e. dense) features of the sample. In this study, the best results were obtained on uncoated samples.

\subsection{Data acquisition and processing}

SEM micro-CT analyses were carried out at the University of Lausanne (Switzerland) using a CamScan MV2300 SEM equipped with a Bruker SEM micro-CT attachment. This device consists of a Princeton Instruments PIXIS XO X-ray camera equipped with a BI CCD detector containing $512 \times 512$ photosites, each $24 \times 24 \mu^{2}$ in size. The detector is cooled down to $-50^{\circ} \mathrm{C}$ by solid-state Peltier elements. The system also includes a computer-controlled motorized stage onto which the cylindrical sample holder is fixed. The parameters used for the acquisition of SEM micro-CT data are shown in Table 1. The low probe current intensity (and therefore the long acquisition time) used in this study was imposed by the limitations of the CamScan MV2300 SEM gun and optics to deliver high probe current intensity along with satisfying beam focusing (s. discussion in Section 5.2).

Bruker's NRecon software (Liu and Sasov, 2005) was used to reconstruct 2D CT slices of the volcanic ash particles from the X-ray shadow projections. The software runs a standard convolution-back-projection procedure based on the inverse Radon transform (Radon, 1917), coupled with a Feldkamp algorithm (Feldkamp et al., 1984) to account for the cone-beam acquisition geometry used. A Gaussian smoothing value $s$ of 2 (with $\sigma=0.25+0.25 \mathrm{~s}$, and $\mathrm{s}>0$; X. Liu, personal communication) was applied to reduce the digital noise in the reconstructed

Table 1

Parameters used for the acquisition of SEM micro-CT data.

\begin{tabular}{lllllllll}
\hline Particles $^{\mathrm{a}}$ & $\begin{array}{l}\text { Voltage } \\
(\mathrm{kV})\end{array}$ & $\begin{array}{l}\text { Current }^{\mathrm{b}} \\
(\mathrm{nA})\end{array}$ & $\begin{array}{l}\text { Capture }_{\text {time }^{\mathrm{c}}} \\
(\mathrm{s})\end{array}$ & $\mathrm{N}^{\mathrm{d}}$ & $\begin{array}{l}\text { Rotation }^{\mathrm{e}} \\
\left({ }^{\circ}\right)\end{array}$ & $\begin{array}{l}\text { Step }^{\mathrm{e}} \\
\left({ }^{\circ}\right)\end{array}$ & $\begin{array}{l}\text { Pixel } \\
\text { size } \\
(\mu \mathrm{m})\end{array}$ & $\begin{array}{l}\text { Duration } \\
(\mathrm{h})\end{array}$ \\
\hline MFM03-1 & 30 & 95 & 18.5 & 6 & 360 & 0.5 & 0.96 & 22.2 \\
MFM03-2 & 30 & 110 & 15.0 & 6 & 360 & 0.5 & 0.96 & 18.0 \\
MFM03-3 & 30 & 105 & 18.0 & 6 & 360 & 0.5 & 0.96 & 21.6 \\
MFM03-4 & 30 & 80 & 22.0 & 6 & 360 & 0.5 & 0.96 & 26.4 \\
MFM20-1 & 30 & 90 & 21.0 & 6 & 360 & 0.5 & 0.96 & 25.2 \\
MFM20-2 & 30 & 105 & 16.0 & 6 & 360 & 0.5 & 0.96 & 19.2 \\
MFM20-3 & 30 & 135 & 14.0 & 6 & 360 & 0.5 & 1.00 & 16.8 \\
MFM20-4 & 30 & 90 & 20.0 & 6 & 360 & 0.5 & 0.96 & 24.0 \\
MFM40-1 & 30 & 90 & 22.0 & 6 & 360 & 0.5 & 0.96 & 26.4 \\
MFM40-2 & 30 & 125 & 14.0 & 6 & 360 & 0.5 & 0.96 & 16.8 \\
MFM40-3 & 30 & 130 & 14.0 & 6 & 360 & 0.5 & 0.96 & 16.8 \\
MFM40-4 & 30 & 85 & 21.0 & 6 & 360 & 0.5 & 1.00 & 25.2 \\
MFM45-1 & 30 & 100 & 20.0 & 6 & 360 & 0.5 & 0.96 & 24.0 \\
MFM45-2 & 30 & 75 & 24.0 & 6 & 360 & 0.5 & 0.96 & 28.8 \\
MFM45-3 & 30 & 120 & 14.5 & 6 & 360 & 0.5 & 0.96 & 17.4 \\
MFM45-4 & 30 & 130 & 14.5 & 6 & 360 & 0.5 & 1.03 & 17.4 \\
MFM03-5 & 30 & 35 & 60.0 & 6 & 360 & 1.0 & 0.50 & 36.0 \\
\hline
\end{tabular}

Notes:

a Collected from the 125-250 $\mu \mathrm{m}$ sieve fraction except sample MFM03-5 (63-125 $\mu \mathrm{m})$.

b Probe current on the brass target.

c Exposure time required to acquire one view.

d Number of collected views at each angular position.

A rotation of $360^{\circ}$ and a step size of $0.5^{\circ}$ were used to privilegiate the quality of CT reconstruction and data sampling over productivity. Choosing a rotation of $180^{\circ}$ and a step size of $1^{\circ}$ would reduce the scan duration by a factor of 4 , but with a negative impact on data quality.

f Scan duration could be reduced by one order of magnitude, either by using the highcurrent (up to $1000 \mathrm{nA}$ ) focused beam generated by the last generation of in-lens thermal field-emission SEM, or by defocussing the electron beam of conventional SEMs. In this latter case, however, optimum resolution cannot be reached (s. discussion). slices, except for sample MFM03-5 ( $s=4)$. Beam hardening was corrected using a correction depth of $30 \%$ to $80 \%$ to account for the preferential attenuation of low-energy X-rays (for details on the mathematics behind linear beam hardening corrections, s. Herman, 1979). Tilt of the rotation axis was compensated digitally when needed. No compensation for mechanical inaccuracies (Mayo et al., 2003; Sasov et al., 2008) was required.

The reconstructed slices were then segmented using Bruker's CTAn software. The segmentation stage consists in assigning each pixel to an object of interest (particle, vesicle or crystal) based upon threshold filtering of grayscale intensities. In case a given phase showed a significant spread in grayscale intensities likely to overlap those of other phases, seeded threshold filtering was used to take into account connectivity information and improve the segmentation process. An updated version of the Blob3D software (Ketcham, 2005) was utilized to generate volume renderings and to separate individual objects. Manual separation was performed to guarantee a reliable determination of the complex textures observed in volcanic ash. Morphological parameters, including sphericity, circularity, axis lengths, elongation, flatness, and shape factors were calculated from the segmented and separated volumes using the new specially-developed functionalities of Blob3D. Because the accuracy of the calculated parameters depends on the magnification factor (ratio of the source-to-detector distance over the source-to-sample distance), and because the magnification factor given by the acquisition software through the so-called "pixel size" (dimension of the sample covered by one pixel edge in the shadow projection) is only indicative (B. Pauwels, personal communication), the true magnification factor (and pixel size) was recalculated for each CT scan. The source-to-detector distance was measured manually on the instrument and the source-to-sample distance was determined using the measurement tool of the SEM imaging system (the magnification of the SEM being calibrated on a reference sample). Finally, 3D animations of the particles were generated using Bruker's CTVox software (Boons, 2010) to allow for visualization of the data.

\subsection{SEM imaging, EDX analysis and resolution test}

To test the validity and limitations of the SEM micro-CT technique, backscatter electron (BSE) images and energy dispersive X-ray (EDX) spectroscopic analyses were collected following SEM micro-CT scanning. Each volcanic ash particle was unglued from the sample holder tip, mounted in vertical position in epoxy resin and ground down. The intention here was not to match the polished surface with a previously selected CT slice, but rather to expose an area of the sample containing the main particle constituents (microcrystals, vesicles, groundmass, and if present, lithic fragments). The exposed sample surface was imaged and the chemical composition of the microcrystals and lithic fragments were determined using a Tescan Mira LMU field emission-SEM operated at $20 \mathrm{kV}$ and $8-23 \mathrm{~mm}$ working distance. BSE images were then compared with the corresponding CT slices.

In order to evaluate the resolving power of SEM micro-CT, a Beametr v1 test sample (aBeam Technologies, Hayward, California, USA) and its dedicated software were used to measure the diameter of the electron probe. The test sample consists of a piece of silicon containing a nanoscale pattern with a known spatial frequency spectrum. Because the spatial frequency spectrum of a recorded image is a function of the beam diameter, a mathematical algorithm can be used to extract the beam diameter from an SEM image of the test pattern (Babin et al., 2006). Monte Carlo simulations using the Casino 2.42 software (Hovington et al., 1997; Drouin et al., 2007) were then performed to determine the size and shape of the X-ray emission volume within the brass target. Input parameters included a target composition of $67 \mathrm{wt} . \% \mathrm{Cu}$ and $33 \mathrm{wt} . \% \mathrm{Zn}$, a number of incoming primary electrons of 50,000, and the electron probe diameter measured using the Beametr v1 test sample. 


\section{Results}

SEM micro-CT, BSE and EDX results for a selection of four volcanic ash particles picked from the 125-250 $\mu \mathrm{m}(2-3 \varphi$ ) sieve fraction (samples MFM03-3, MFM20-3, MFM40-3 and MFM45-4) and the particle from the 64-125 $\mu \mathrm{m}(3-4 \varphi)$ sieve fraction (sample MFM03-5) are shown in Fig. 2. A movie with animated volume renderings of the particles, vesicles and crystals for each of the seventeen analyzed samples can be downloaded from the supplementary data available online (http://dx.doi.org/10.1016/j.jvolgeores.2014.11.016).

\subsection{Quality of CT data}

X-ray shadow projections are sharp, well-defining the contours of the particles. This suggests that the X-ray emission cross-section in the brass target was significantly smaller than the area of the sample covered by one pixel in the X-ray shadow projections. The signal-to-noise ratio was kept to a moderate level by using a long acquisition time to compensate for the weak probe current intensity imposed by the specifications of the SEM.

Reconstructed CT slices are only slightly affected by the artifacts commonly reported in conventional CT work, such as beam hardening (e.g. MFM03-3) or ring artifacts. Two samples (MFM40-3, MFM40-4) show straight or slightly curved black streaks of unknown origin, which cannot be correlated with any obvious textural features within the particles. Gold-coating the samples has a negative influence on the quality of the CT slices as it induces a bright border at the particlevacuum interface (e.g. MFM20-3, MFM20-4), which has similar grayscale intensities as dense microcrystals (e.g. spinel). In case dense objects have to be segmented and separated this bright border should be erased manually in each slice after threshold filtering. Uncoated particles (e.g. MFM03-5, MFM45-4) have intensities along particle-vacuum interfaces roughly similar to that of the bulk, thus facilitating the threshold filtering procedure.

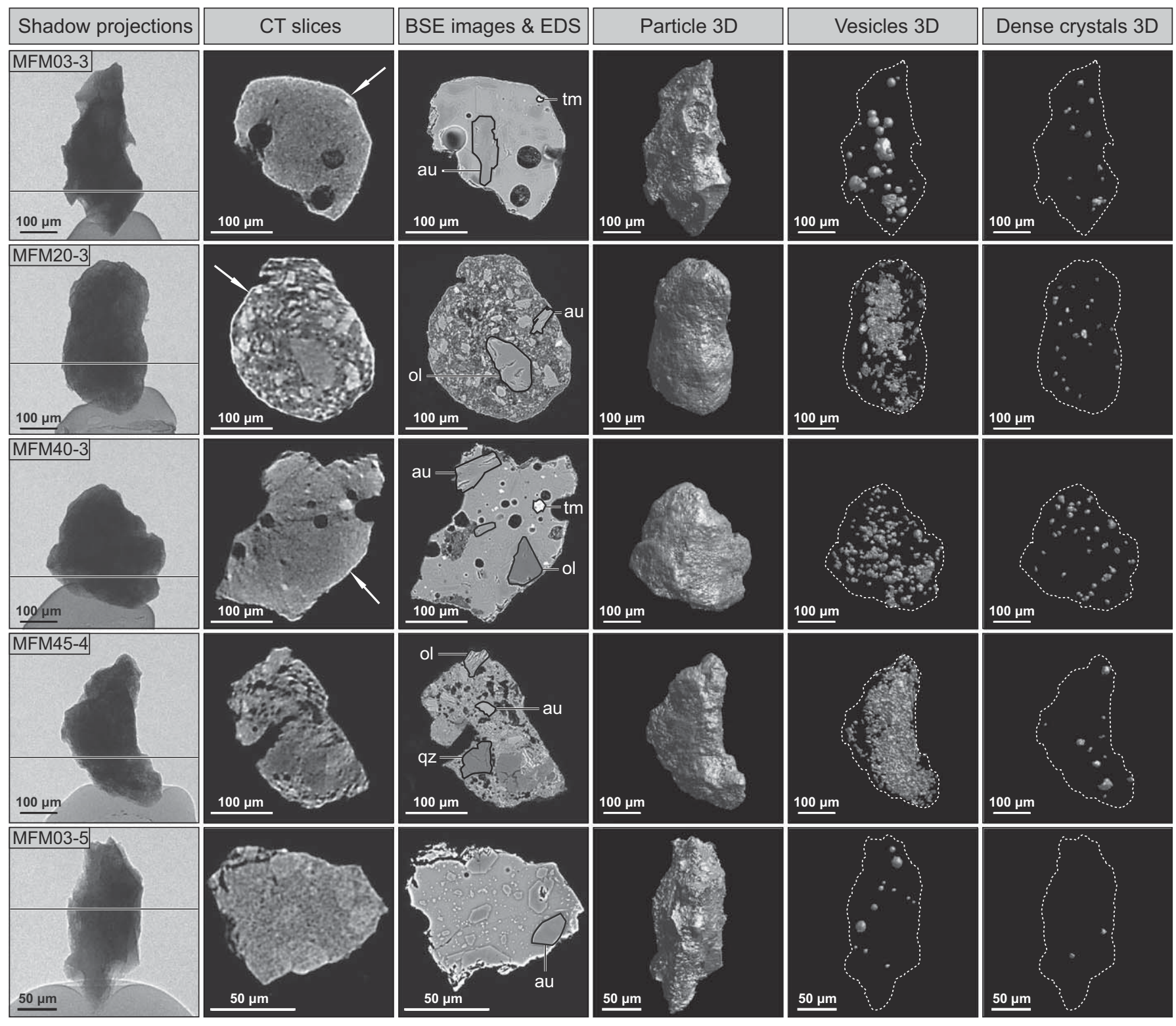

Fig. 2. X-ray shadow projections, CT slices, SEM data and volume renderings for particles, vesicles and dense microcrystals for a selection of five volcanic ash particles from the $125-250 \mu \mathrm{m}$ (MFM03-3, MFM20-3, MFM40-3, MFM45-4) and from the 64-125 $\mu \mathrm{m}$ (MFM03-5) sieve fractions. The approximate position of the CT slices and SEM images is shown by a horizontal line in the shadow projection. To allow for a best possible match between the CT slices and the SEM images (perfectly equivalent positioning cannot be guaranteed during the preparation of both sample types), the CT slice views have been slightly tilted to match the SEM views. Arrows indicate the bright border resulting from gold coating. Mineral abbreviations are: au: augite, qz: quartz, ol: olivine, tm: titanomagnetite. A movie for each of the seventeen analyzed samples can be downloaded from the following address: http://dx.doi.org/10.1016/j.jvolgeores.2014.11.016. 
Comparison of the BSE images with the corresponding CT slices indicates that most of the trapped vesicles are clearly identifiable. Because of the obvious X-ray attenuation contrast between vacuum and glass, the vesicle walls are sharp except when the vesicles are filled with secondary calcite (e.g. MFM03-3). Microcrystals and lithic fragments are generally hard to distinguish, as the difference in X-ray mass attenuation coefficients with the surrounding groundmass is small (Table 2), thus leading to an overlap in grayscale intensities. This difficulty, already reported in Baker et al. (2012), is further amplified by the low to moderate signal-to-noise ratio observed in the X-ray shadow projections. Microcrystals of olivine and augite are generally not identified when trapped in a glassy (sideromelane) groundmass (MFM03-1, MFM03-2, MFM03-3, MFM03-4, MFM20-1, MFM20-4, MFM40-1, MFM40-3, MFM40-4), but they are discernable in particles with a tachylitic groundmass (MFM20-3, MFM40-2, MFM45-1, MFM45-2, MFM45-3, MFM45-4). Since the X-ray mass attenuation coefficients for both groundmass types are very close $\left(61.0\right.$ vs $\left.63.2\left[\mathrm{~cm}^{2} / \mathrm{g}\right]\right)$, this feature may be explained by a difference in texture. The glassy groundmass is homogeneous, i.e. uniformly gray in CT slices (as are the microcrystals), whereas the tachylitic groundmass is made of adjacent dark and bright areas corresponding to small-scale voids and crystallites. Thus, the degree of homogeneity of the groundmass ultimately determines the visibility of olivine and augite microcrystals. The overlap in grayscale intensities between the microcrystals and the groundmass is, however, too significant to make any segmentation successful, even for the particles with a tachylitic groundmass. Dense minerals such as spinel, zircon and titanomagnetite are easily identified, both in glassy (sideromelane) and tachylitic groundmasses, and they can be successfully segmented and reconstructed. No distinction can be made between the different dense mineral species based on their grayscale intensities alone.

In the supplementary movies, the reconstructed volumes often display bright straight lines with interspaces varying as the particles rotate. These lines are artifacts caused by the rendering algorithm employed by the CTVox software (S. Boons, personal communication). The effect is amplified when the CT slices used to generate the movie have sharp greyscale boundaries. This is obviously the case here as the CT slices have been converted to di- and trichromic greyscale images to allow for a better identification of features. In the movies displaying dense

Table 2

$\mathrm{X}$-ray mass attenuation coefficients calculated for a photon energy $\mathrm{E}=8.8 \mathrm{kV}$.

\begin{tabular}{|c|c|c|c|c|c|c|c|c|}
\hline Elements & au & ol & $\mathrm{tm}$ & $\mathrm{sp}$ & $\mathrm{zr}$ & $\mathrm{qz}$ & tac & sid \\
\hline 0 & 41.9 & 42.4 & 28.3 & 33.6 & 34.9 & 53.3 & 41.8 & 44.2 \\
\hline $\mathrm{Na}$ & 0.0 & 0.0 & 0.0 & 0.0 & 0.0 & 0.0 & 2.1 & 2.6 \\
\hline $\mathrm{Mg}$ & 7.9 & 27.3 & 0.0 & 5.3 & 0.0 & 0.0 & 4.1 & 1.0 \\
\hline $\mathrm{Al}$ & 4.2 & 0.0 & 0.0 & 5.0 & 0.0 & 0.0 & 6.3 & 8.2 \\
\hline $\mathrm{Si}$ & 22.7 & 19.0 & 0.0 & 0.6 & 15.3 & 46.7 & 20.2 & 20.2 \\
\hline $\mathrm{Cl}$ & 0.0 & 0.0 & 0.0 & 0.0 & 0.0 & 0.0 & 0.0 & 0.3 \\
\hline K & 0.4 & 0.0 & 0.0 & 0.0 & 0.0 & 0.0 & 0.2 & 3.3 \\
\hline $\mathrm{Ca}$ & 16.0 & 0.2 & 0.0 & 0.7 & 0.0 & 0.0 & 11.9 & 9.1 \\
\hline $\mathrm{Ti}$ & 1.6 & 0.0 & 7.7 & 6.0 & 0.0 & 0.0 & 2.1 & 1.7 \\
\hline $\mathrm{Cr}$ & 0.4 & 0.0 & 1.8 & 0.4 & 0.0 & 0.0 & 0.0 & 0.0 \\
\hline Mn & 0.0 & 0.2 & 0.4 & 0.4 & 0.0 & 0.0 & 0.2 & 0.1 \\
\hline $\mathrm{Fe}$ & 5.0 & 10.5 & 61.6 & 47.6 & 0.0 & 0.0 & 9.3 & 9.0 \\
\hline $\mathrm{Ni}$ & 0.0 & 0.3 & 0.2 & 0.1 & 0.0 & 0.0 & 0.0 & 0.0 \\
\hline $\mathrm{Zr}$ & 0.0 & 0.0 & 0.0 & 0.0 & 49.8 & 0.0 & 0.0 & 0.0 \\
\hline$\mu / \rho\left[\mathrm{cm}^{2} / \mathrm{g}\right]$ & 58.1 & 50.9 & 171.3 & 137.1 & 75.2 & 29.5 & 63.2 & 61.0 \\
\hline
\end{tabular}

Notes: $\mathrm{X}$-ray mass attenuation coefficients have been calculated by simple additivity using the equation $\mu / \rho=\sum_{i} w_{i}(\mu / \rho)_{i}$. The weight fractions (wt.\%) for element $i, w_{i}$, have been obtained from EDX analyses performed in sample MFM03, except for quartz and zircon for which the stoichiometric pure phases have been taken. The elemental mass attenuation coefficients, $(\mu / \rho)_{i}$, are from the NIST database (Hubbell and Seltzer, 2007). The Xray attenuation coefficients corresponding to $8.8 \mathrm{kV}$ (average of the two main characteristic X-ray energies produced by a brass target) have been obtained by linear interpolation between the two tabulated data at 8.0 and $10.0 \mathrm{kV}$, except for Ni, for which the value for the absorption edge at $8.33 \mathrm{kV}$ has been taken. Abbreviations are: au: augite, ol: olivine, tm: titanomagnetite, sp: spinel, zr: zircon, qz: quartz, tac: tachylitic groundmass, sid: sideromelane (glassy groundmass). crystals a horizontal texture related to the slice-by-slice removal of the gold-coating border may be observed.

\subsection{Three-dimensional data for particles, vesicles and crystals}

Comparison of the X-ray shadow projections with volume renderings shows a good correspondence of morphological features. A wide spectrum of particle shapes can be observed, ranging from irregular shards with concave surface features consisting of broken vesicle walls (MFM03-1, MFM03-2, MFM03-3, MFM03-4, MFM03-5) to sub-rounded oblong particles lacking distinctive surface markings (MFM20-3). Moderately platy (MFM40-1, MFM45-1, MFM45-4) and elongate particle shapes (MFM03-4, MFM20-4) have also been observed.

The shape and spatial distribution of the vesicles in the studied samples are highly variable and can be correlated with the type of groundmass. Particles with glassy groundmass (sideromelane) typically show a few tens of homogeneously distributed and mostly spherical vesicles. The size of the vesicles is variable, but it tends to be larger in MFM03 samples (MFM03-1, MFM03-3, MFM03-4) than in the other samples with a glassy groundmass (MFM20-1, MFM40-1, MFM40-3, MFM404). The smaller size of the vesicles in sample MFM03-2 is related to the small volume of the particle itself. Sample MFM20-4 has a very low porosity ( $\sim 0.5$ vol.\%) mostly consisting of cracks and interstitial pores between groundmass and crystals. In all particles with a glassy groundmass, the vesicles show only rare connectivity between each other.

Particles containing a tachylitic groundmass typically show a large number of irregular pores, which form a network between the numerous imbricated microlites. The intrinsic nature of the tachylitic groundmass therefore prevents vesicles from developing a spherical shape. Samples MFM20-2, MFM20-3 and MFM40-2 show a widespread and mostly interconnected network of irregularly-shaped pores spreading through the tachylitic groundmass. In particles from layer MFM45 (MFM45-1, MFM45-3, MFM45-4) a closely packed arrangement of pores with uniform sizes is observed. The connectivity between pores is high (MFM45-1, MFM45-4) to moderate (MFM45-2, MFM45-3).

Dense minerals are generally small in size $(<15 \mu \mathrm{m}$ in diameter) with a distribution largely depending on the volume already occupied by major minerals, such as olivine and augite. The amount of dense minerals is very variable, ranging from none in sample MFM03-2 to about 300 in sample MFM20-4 ( 50,000 per $\left.\mu^{3}\right)$. Because the manual separation of dense crystals from the gold-coated borders opens the door to potential errors in the segmented volumes, and because no distinction can be made between the different dense mineral species, the morphological parameters for those minerals have not been quantified.

\subsection{Quantification of morphological features}

Calculations of morphological features for all seventeen ash particles including the shape factors increasingly used in ash transport and dispersal models are shown in Table 3. The axis lengths $\mathrm{a}, \mathrm{b}$ and $\mathrm{c}$ used to calculate the shape factor of Wilson and Huang (1979) were deliberately defined as (a) the longest particle dimension, (b) the longest dimension perpendicular to (a), and (c) the dimension perpendicular to both (a) and (b) to stick to the author's definition. This method, however, is subject to controversy and more recent texts prefer measuring (b) and (c) based on the smallest projected area, and (a) perpendicular to (b) and (c) (s. Blott and Pye, 2008 for a review). Sphericity and circularity values were calculated using the standard definition of Blott and Pye (2008), i.e. with the particle dimensions as the denominator and the equivalent circle/sphere dimensions as the numerator. Doing so, sphericity and circularity values always range between 0 and 1 , and the shape factor of Dellino et al. (2005) becomes the product of sphericity and circularity instead of its ratio. The shape factor of Ganser (1993), also frequently used in ash transport and dispersion models, was not 
Table 3

Particle morphological data.

\begin{tabular}{|c|c|c|c|c|c|c|c|c|c|c|c|c|c|c|}
\hline \multirow[t]{2}{*}{ Particles } & \multirow{2}{*}{$\begin{array}{l}\text { Volume }^{\mathrm{a}} \\
\mathrm{V} \\
\left(\mathrm{mm}^{3}\right)\end{array}$} & \multirow{2}{*}{$\begin{array}{l}\begin{array}{l}\text { Surface } \\
\text { area }\end{array} \\
\mathrm{S} \\
\left(\mathrm{mm}^{2}\right)\end{array}$} & \multirow{2}{*}{$\begin{array}{l}\mathrm{S} / \mathrm{V} \\
\frac{\left(\mathrm{mm}^{-1}\right)}{}\end{array}$} & \multirow{2}{*}{$\begin{array}{l}\text { Aspect } \\
\text { ratio }^{\mathrm{b}}\end{array}$} & \multirow[t]{2}{*}{ Sphericity $^{\mathrm{c}}$} & \multirow[t]{2}{*}{ Circularity $^{\mathrm{d}}$} & \multirow{2}{*}{$\begin{array}{l}\text { Max. projected } \\
\text { area } \\
\left(\mathrm{mm}^{2}\right)\end{array}$} & \multicolumn{3}{|c|}{ Axis lengths ${ }^{\mathrm{e}}$} & \multirow{2}{*}{$\begin{array}{l}\text { Elongation }^{\mathrm{e}} \\
\mathrm{b} / \mathrm{a}\end{array}$} & \multirow{2}{*}{$\begin{array}{l}\text { Flatness }^{\mathrm{e}} \\
\mathrm{c} / \mathrm{b}\end{array}$} & \multicolumn{2}{|l|}{ Shape factors } \\
\hline & & & & & & & & $\begin{array}{l}\mathrm{a} \\
(\mathrm{mm})\end{array}$ & $\begin{array}{l}\mathrm{b} \\
(\mathrm{mm})\end{array}$ & $\begin{array}{l}\mathrm{c} \\
(\mathrm{mm})\end{array}$ & & & $\begin{array}{l}\text { Dellino et al. } \\
(2005)^{\mathrm{f}}\end{array}$ & $\begin{array}{l}\text { Wilson and } \\
\text { Huang }(1979)^{\mathrm{g}}\end{array}$ \\
\hline MFM03-1 & 0.0104 & 0.39 & 37 & 2.0 & 0.59 & 0.72 & 0.090 & 0.45 & 0.32 & 0.27 & 0.70 & 0.85 & 0.43 & 0.64 \\
\hline MFM03-2 & 0.0031 & 0.15 & 49 & 1.8 & 0.68 & 0.88 & 0.046 & 0.27 & 0.25 & 0.16 & 0.92 & 0.63 & 0.59 & 0.75 \\
\hline MFM03-3 & 0.0074 & 0.35 & 48 & 2.2 & 0.52 & 0.83 & 0.085 & 0.46 & 0.30 & 0.19 & 0.64 & 0.64 & 0.43 & 0.53 \\
\hline MFM03-4 & 0.0046 & 0.22 & 47 & 2.3 & 0.61 & 0.78 & 0.064 & 0.40 & 0.22 & 0.20 & 0.56 & 0.88 & 0.48 & 0.52 \\
\hline MFM20-1 & 0.0031 & 0.15 & 49 & 2.4 & 0.68 & 0.85 & 0.051 & 0.31 & 0.23 & 0.14 & 0.74 & 0.60 & 0.58 & 0.59 \\
\hline MFM20-2 & 0.0049 & 0.24 & 49 & 1.9 & 0.58 & 0.86 & 0.059 & 0.35 & 0.24 & 0.20 & 0.68 & 0.86 & 0.49 & 0.63 \\
\hline MFM20-3 & 0.0119 & 0.32 & 27 & 2.2 & 0.79 & 0.87 & 0.092 & 0.43 & 0.32 & 0.22 & 0.75 & 0.69 & 0.68 & 0.63 \\
\hline MFM20-4 & 0.0061 & 0.24 & 39 & 2.6 & 0.68 & 0.84 & 0.073 & 0.43 & 0.24 & 0.16 & 0.56 & 0.67 & 0.57 & 0.47 \\
\hline MFM40-1 & 0.0036 & 0.18 & 49 & 2.5 & 0.64 & 0.80 & 0.057 & 0.32 & 0.29 & 0.16 & 0.92 & 0.54 & 0.52 & 0.71 \\
\hline MFM40-2 & 0.0075 & 0.28 & 37 & 2.2 & 0.67 & 0.82 & 0.070 & 0.42 & 0.26 & 0.21 & 0.61 & 0.81 & 0.55 & 0.55 \\
\hline MFM40-3 & 0.0090 & 0.27 & 30 & 1.5 & 0.78 & 0.88 & 0.074 & 0.35 & 0.31 & 0.24 & 0.89 & 0.79 & 0.69 & 0.80 \\
\hline MFM40-4 & 0.0081 & 0.27 & 33 & 2.1 & 0.72 & 0.89 & 0.085 & 0.39 & 0.33 & 0.21 & 0.83 & 0.63 & 0.64 & 0.68 \\
\hline MFM45-1 & 0.0044 & 0.22 & 50 & 2.8 & 0.59 & 0.87 & 0.066 & 0.34 & 0.29 & 0.14 & 0.86 & 0.49 & 0.51 & 0.64 \\
\hline MFM45-2 & 0.0056 & 0.24 & 43 & 1.7 & 0.64 & 0.89 & 0.057 & 0.33 & 0.27 & 0.22 & 0.82 & 0.81 & 0.57 & 0.74 \\
\hline MFM45-3 & 0.0073 & 0.25 & 34 & 1.9 & 0.73 & 0.84 & 0.072 & 0.36 & 0.31 & 0.20 & 0.86 & 0.65 & 0.62 & 0.71 \\
\hline MFM45-4 & 0.0097 & 0.33 & 34 & 2.5 & 0.67 & 0.82 & 0.095 & 0.44 & 0.33 & 0.18 & 0.76 & 0.55 & 0.55 & 0.59 \\
\hline MFM03-5 & 0.0011 & 0.08 & 73 & 2.4 & 0.65 & 0.76 & 0.023 & 0.25 & 0.16 & 0.10 & 0.66 & 0.63 & 0.50 & 0.54 \\
\hline
\end{tabular}

Notes:

a Volume of the particle external envelope.

b Calculated from the best-fit ellipsoid.

c Ratio of the surface area of a sphere with equivalent volume as the particle $\left(A_{\text {sphere }}\right)$ to the actual surface area of the particle $\left(A_{\text {particle }}\right)$.

d Ratio of the perimeter of a circle with equivalent area as the particle maximum projection area $\left(\mathrm{P}_{\text {circle }}\right)$ to the actual perimeter of the particle maximum projection area ( $\mathrm{P}_{\text {particle). }}$.

e With (a) the longest particle dimension, (b) the longest dimension perpendicular to (a), and (c) the dimension perpendicular to both (a) and (b).

${ }^{\mathrm{f}}$ Ratio of sphericity to circularity, with circularity defined as $\mathrm{P}_{\text {particle }} / \mathrm{P}_{\text {circle }}$ (s. Dellino et al., 2005; pp. 2-3). Using the standard definition of circularity ( $\mathrm{P}_{\text {circle }} / \mathrm{P}_{\text {particle }}$ ), the shape factor corresponds to the product of sphericity and circularity values.

$\mathrm{g}$ Defined as $(\mathrm{b}+\mathrm{c}) / 2 \mathrm{a}$ (Wilson and Huang, 1979).

calculated as it requires previous knowledge of the particle motion, which is beyond the scope of this study.

Table 4 shows the porosity data of the particles presented in Table 3. For particles with a tachylitic groundmass characterized by an interconnected porosity network, single vesicle dimensions have been calculated. The number, density distribution and volume of the vesicles vary significantly from one particle to the next, with consequences on the overall particle porosity. Comparison of the number of vesicles $>200 \mu \mathrm{m}^{3}$ in sample MFM03-5 (64-125 um sieve fraction) with the other MFM03 samples (125-250 $\mu \mathrm{m}$ sieve fraction) and with the vesicularity of lapillus-sized particles collected in the same stratigraphic tephra layer (e.g. up to 60 vol.\% for MFM03) shows that the pore volume and vesicle number are highly dependent on particle size. The main reason is that small particle shapes have been influenced by large shattered bubbles, whereas in larger particles those bubbles are trapped inside the bulk volume and therefore form enclosed vesicles. Small volcanic ash particles are thus deprived from the volume contribution of larger vesicles.

\section{Discussion}

\subsection{Spatial resolution and detectability}

Determining the spatial resolution of the SEM micro-CT technique is a complex issue involving several parameters, some of which are not

Table 4

Porosity data ${ }^{a}$.

\begin{tabular}{|c|c|c|c|c|c|c|c|}
\hline Particles & Matrix & Porosity type & $\begin{array}{l}\text { Pore volume } \\
(\%)\end{array}$ & $\begin{array}{l}\text { Number of vesicles } \\
(\mathrm{N})\end{array}$ & $\begin{array}{l}\text { Vesicle density distribution } \\
\left(\mathrm{N} / \mathrm{mm}^{3}\right)\end{array}$ & $\begin{array}{l}\text { Median vesicle volume } \\
\left(\mathrm{mm}^{3}\right)\end{array}$ & $\begin{array}{l}\text { Average vesicle volume } \\
\left(\mathrm{mm}^{3}\right)\end{array}$ \\
\hline MFM03-1 & Glassy & Closed vesicles & 2.5 & 62 & 5975 & 0.00000059 & 0.0000041 \\
\hline MFM03-2 & Glassy & Closed vesicles & 2.0 & 39 & 12,781 & 0.00000041 & 0.0000016 \\
\hline MFM03-3 & Glassy & Closed vesicles & 2.3 & 35 & 4759 & 0.00000085 & 0.0000048 \\
\hline MFM03-4 & Glassy & Closed vesicles & 2.5 & 26 & 5611 & 0.00000066 & 0.0000044 \\
\hline MFM20-1 & Glassy & Closed vesicles & 1.2 & 17 & 5443 & 0.00000036 & 0.0000022 \\
\hline MFM20-2 & Tachylitic & Interconnected network & 8.2 & - & - & - & - \\
\hline MFM20-3 & Tachylitic & Interconnected network & 1.6 & - & - & - & - \\
\hline MFM20-4 & Glassy & Cracks/interstitials & 0.5 & - & - & - & - \\
\hline MFM40-1 & Glassy & Closed vesicles & 5.0 & 94 & 26,001 & 0.00000054 & 0.0000019 \\
\hline MFM40-2 & Tachylitic & Interconnected network & 7.3 & - & - & - & - \\
\hline MFM40-3 & Glassy & Closed vesicles & 1.8 & 167 & 18,573 & 0.00000042 & 0.0000010 \\
\hline MFM40-4 & Glassy & Closed vesicles & 2.8 & 147 & 18,250 & 0.00000041 & 0.0000015 \\
\hline MFM45-1 & Tachylitic & Interconnected network & 16.9 & - & - & - & - \\
\hline MFM45-2 & $-{ }^{\mathrm{b}}$ & Intermediate & 9.4 & 198 & 35,465 & 0.00000057 & 0.0000027 \\
\hline MFM45-3 & Tachylitic & Intermediate & 4.2 & 164 & 22,533 & 0.00000051 & 0.0000018 \\
\hline MFM45-4 & Tachylitic & Interconnected network & 6.9 & - & - & - & - \\
\hline MFM03-5 & Glassy & Closed vesicles & 0.3 & 3 & 2823 & 0.00000127 & 0.0000009 \\
\hline
\end{tabular}

Notes:

Only vesicles with volume $>200 \mu \mathrm{m}^{3}$ (corresponding equivalent sphere diameter of $7.25 \mu \mathrm{m}$ ) were taken into account (s. discussion)

b Unknown matrix type as the sample was lost during sample preparation prior SEM imaging. 
fully quantifiable. A primary distinction has to be made between the resolution that can be obtained in the X-ray shadow projections and the resolution that can be expected in the reconstructed CT slices. In addition, the resolution has to be distinguished from the effective detectability of textural features.

The spatial resolution achievable for the X-ray shadow projections depends on (1) the size of the X-ray emission volume in the target, (2) the magnification factor (ratio of the source-to-detector distance over the source-to-sample distance), (3) the physical size of the photosites and their interaction, and (4) the X-ray scattering effects. The factor (2) is imposed by the SEM chamber geometry and the size of the sample; the factor (3) is determined by the intrinsic specifications of the X-ray camera; and the factor (4) consists in physical processes occurring within the sample. Hence, only the factor (1) can be influenced by the operator to improve the resolution of the X-ray shadow projections. The size of the X-ray emission volume can be minimized by decreasing the voltage of the electron beam, or by reducing the diameter of the probe on the target, or by modifying the target composition and shape. In practice, however, the voltage of the electron beam is kept to its highest value $(30 \mathrm{kV})$ in all but the smallest samples, in order to maximize the penetrative power of $\mathrm{X}$-rays.

Reducing the probe diameter potentially improves the spatial resolution but at the cost of a dramatic decrease in signal intensity. Fig. 3 shows a resolution test performed on the Beametr v1 test sample (aBeam Technologies, Hayward, California, USA) using the CamScan MV2300 SEM operated at a probe current of $0.5 \mathrm{nA}$ (standard value
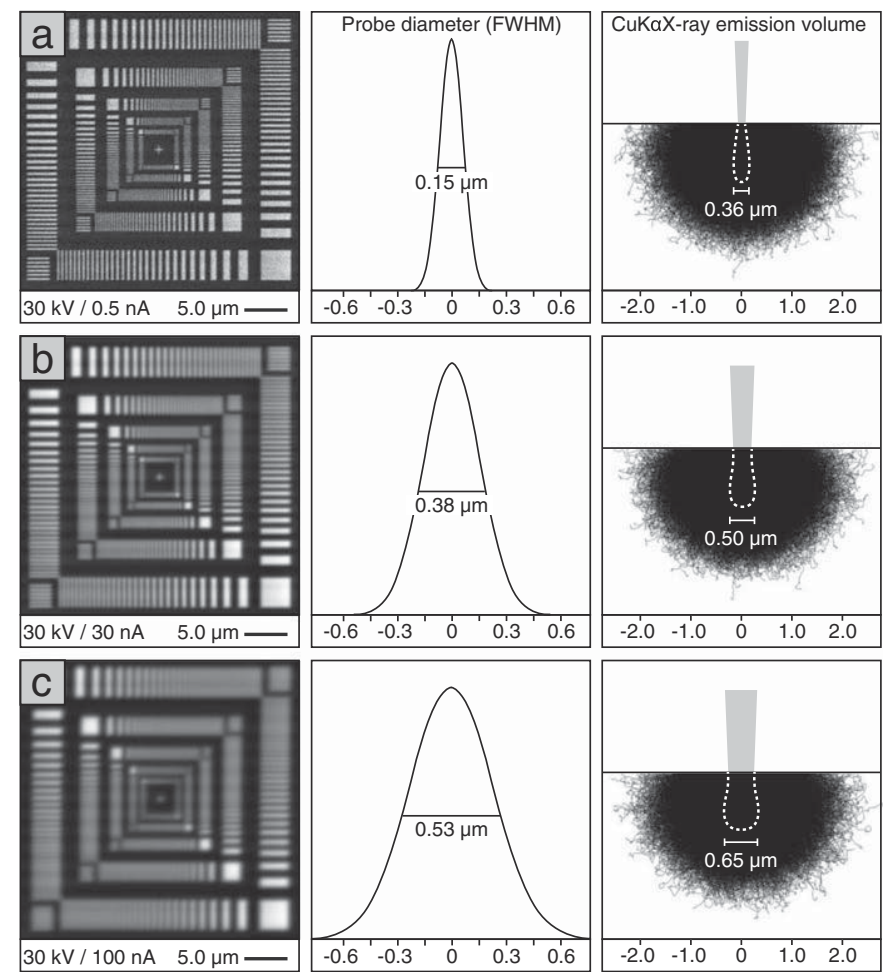

Fig. 3. Beametr v1 test pattern image, calculated probe diameters, and Monte Carlo simulations of CuK $\alpha$ X-ray emission volumes for beam conditions of (a) $30 \mathrm{kV} / 0.5 \mathrm{nA}$ (standard conditions used for SEM imaging), (b) $30 \mathrm{kV} / 30 \mathrm{nA}$ (SEM micro-CT on sample MFM03-5), and (c) $30 \mathrm{kV} / 100 \mathrm{nA}$ (SEM micro-CT on the 125-250 $\mu \mathrm{m}$ particles). FWHM is for full width at half maximum intensity. The trajectories of electrons within the brass target are shown in black and the emission volumes of $90 \% \mathrm{CuK} \alpha \mathrm{X}$-rays are indicated by a white dashed line. The emission volumes of $\mathrm{ZnK} \alpha \mathrm{X}$-rays are not shown as they are almost identical to those of $\mathrm{CuK} \alpha$. Input parameters used for the simulations include a brass composition of $67 \mathrm{wt} . \% \mathrm{Cu}$ and $33 \mathrm{wt} . \% \mathrm{Zn}$ (density: $8.33 \mathrm{~g} / \mathrm{cm}^{3}$ ) and a number of incoming primary electron of 50,000. Note the increase in probe diameter and X-ray emission width along with electron beam intensity. for imaging with conventional SEMs), $30 \mathrm{nA}$ (SEM micro-CT on sample MFM03-5) and $100 \mathrm{nA}$ (SEM micro-CT on the 125-250 $\mu \mathrm{m}$ ash particles). The probe current intensity is clearly a function of the probe diameter: $0.15 \mu \mathrm{m}$ at $0.5 \mathrm{nA}, 0.38 \mu \mathrm{m}$ at $30 \mathrm{nA}$, and $0.53 \mu \mathrm{m}$ at $100 \mathrm{nA}$. Monte Carlo simulations indicate CuK $\alpha \mathrm{X}$-ray emission volumes of $0.36 \mu \mathrm{m}$ in width at $0.5 \mathrm{nA}, 0.50 \mu \mathrm{m}$ at $30 \mathrm{nA}$, and $0.65 \mu \mathrm{m}$ at $100 \mathrm{nA}$. This latter value is very similar to that of Pauwels et al. (2010), who reported a spatial resolution of $\sim 0.7 \mu \mathrm{m}$ using a conventional thermionic SEM and a bulk brass target. Given the very long acquisition time imposed by current intensities below $100 \mathrm{nA}$, the value of $0.65 \mu \mathrm{m}$ can be considered the practical resolution limit for X-ray shadow projections using a standard SEM such as the CamScan MV2300. If acquisition time is not a concern, this value can be pushed down to $0.50 \mu \mathrm{m}$ at $30 \mathrm{nA}$. It must be noted that the width of the X-ray emission volume can be considered the resolution of the shadow projections only if the pixel size (dimension of the sample covered by one pixel edge in the shadow projection) is much smaller than the width of the X-ray emission volume. In a situation where the pixel size is larger than the $\mathrm{X}$-ray emission volume, the resolution of the shadow projection becomes primarily a function of the pixel size, or more precisely, twice the pixel size as the projected image of the X-ray emission volume may impinge on two adjacent pixels (partial volume effect). In this study, the pixel size was $\sim 1 \mu \mathrm{m}$ for all samples except MFM03-5 (s. Table 1). Using $0.65 \mu \mathrm{m}$ for the width of the X-ray emission volume, the upper bound for spatial resolution of the shadow projections is therefore $\sim 2 \mu \mathrm{m}$. Following the same logic for sample MFM03-5 (width of the X-ray emission volume and pixel size: $0.50 \mu \mathrm{m}$ ), the resolution for the shadow projections would be $\sim 1 \mu \mathrm{m}$.

An alternative way to reduce the size of the X-ray emission volume involves a modification of the target composition and/or shape. Bulk targets designed in high atomic number metals, such as gold or platinum, have the advantage of confining the X-ray source to a smaller volume than those made of brass or titanium. However, targets of this kind are not appropriate for CCD detectors with quantum efficiency optimized for X-rays below $10 \mathrm{kV}$, such as the BI CCD detector of the Princeton PIXIS XO X-ray camera (Pauwels et al., 2010). Using high atomic number targets, a gain in resolution down to $\sim 0.4 \mu \mathrm{m}$ can be expected in the X-ray shadow projections, but at the cost of a significant decrease in the signal-to-noise ratio, which compromises the discrimination of phases during the segmentation stage. Thin layer targets have been used to limit the size of the X-ray source to the narrow neck of the interaction volume (Mayo et al., 2003; Bruyndonckx et al., 2010; Sasov et al., 2010a) and to improve the spatial resolution in X-ray shadow projections down to $\sim 0.15 \mu \mathrm{m}$. However, because the interaction volume in such targets is small, the X-ray flux is much weaker, which results in low signal-to-noise ratio in the image and hence excessive acquisition time. Targets with special geometries, such as sharp $\mathrm{Pt} / \mathrm{Ir}$ tips, have been designed to generate even smaller emission volumes in the axial direction of the X-ray camera (Sasov et al., 2010a, 2010b). These novel types of targets make possible the acquisition of $\mathrm{X}$-ray shadow projections with spatial resolution as low as $\sim 0.05 \mu \mathrm{m}$, but again at the cost of a very significant decrease in X-ray flux compared to bulk targets (B. Pauwels, personal communication). In addition, the increase in spatial resolution provided by sharp tips can only be fully exploited at a very small source-to-sample distance $(<1 \mathrm{~mm})$, i.e. for a high magnification factor. For geometrical reasons, such a short distance is not compatible with the study of volcanic ash particles of the 125-250 $\mu \mathrm{m}$ sieve fraction, as the area covered by the particle projection would exceed the area of the detector. Studying such particles leaves therefore very little flexibility for the operator to reduce the size of the X-ray emission volume. In practice, the size of the Xray emission volume within the target is kept small by keeping the probe diameter as small as possible. Using a conventional thermionic source, this implies the use of low probe current intensities. The resulting loss of flux has to be compensated by an increase in acquisition time to keep the signal-to-noise ratio constant in the X-ray shadow projections. 
When considering the spatial resolution that can be expected in the $\mathrm{CT}$ slices reconstructed from the X-ray shadow projections, additional factors are important. These include (1) the mechanical accuracy of the stepping motorized stage, (2) possible mechanical and thermal sample instability during scanning, (3) drift of the electron beam on the target, (4) simplifications of the reconstruction algorithm, and (5) Gaussian smoothing applied to the data. Thus, even if (1) can be largely compensated during post-processing using a forward projection iterative scheme (Mayo et al., 2003; Sasov et al., 2008), (2) can be avoided by skillful sample preparation, (3) and (4) can be kept to a minimum using the most recent SEMs and reconstruction procedures, and (5) is largely imposed by the amount of digital noise, the spatial resolution that can be achieved for the CT slices is always worse than that achievable for X-ray shadow projections. Those parameters are hard to quantify but their effects on the final resolution can be assessed on the basis of the reconstructed CT slices. Visual inspection of the CT slices for sample MFM03-5 show that 3 pixels, i.e. $~ 1.5 \mu \mathrm{m}$, are needed to delimit a sharp boundary between two media having very different X-ray attenuation coefficients (Fig. 4). The point-spread function (PSF) tool recently implemented into the Blob3D software (Ketcham and Hildebrandt, 2014 ) yields a very similar value (3.06 pixels averaged over 10 traverses). If the Rayleigh criterion is applied, only details of this order of magnitude can be considered as resolved in the CT slices.

In addition, it must be kept in mind that the spatial resolution is not the sole parameter intervening in the detectability of features within the sample. Detectability also depends on the textural complexity of the sample, the difference in X-ray attenuation coefficient between nearby elements, the resulting contrast difference between adjacent pixels, and above all, the signal-to-noise ratio. Besides this, to consider a given feature as unambiguously detected more than one pixel/voxel is needed. Gualda and Rivers (2006) reported that only features with more than 4 pixels in diameter (i.e. 34 voxels in total when considering spherical objects) can be detected unequivocally. In case CT slices are blurred or noisy, this value has to be extended to avoid segmenting false objects. Assuming that a sharp boundary in the CT slices of particle MFM03-5 is delimited by 3 pixels (with the boundary assumed to be located half way along those 3 pixels), the minimum diameter of a recognizable object has to be extended to 7 pixels ( 180 voxels in total). This corresponds to features of approximately $\sim 3.5 \mu \mathrm{m}$ in diameter $\left(\sim 20 \mu \mathrm{m}^{3}\right)$. For such small features, errors in the calculations of morphological parameters (length, volume, surface area...) will be larger than for more voluminous objects. Following the same reasoning the minimum size for vesicles and crystals presented in Fig. 2, Table 4 and the supplementary data has been fixed to $200 \mu^{3}$. This value was chosen based on the sample having the lowest CT slice quality in order to enable comparison of morphological features within the whole sample set. This assumption lies clearly on the cautious side, as the data of most particles would have allowed for reconstruction of smaller volumes.

To sum up, a spatial resolution of $0.65 \mu \mathrm{m}$ can be achieved in the X-ray shadow projections using a bulk brass target in a standard SEM equipped

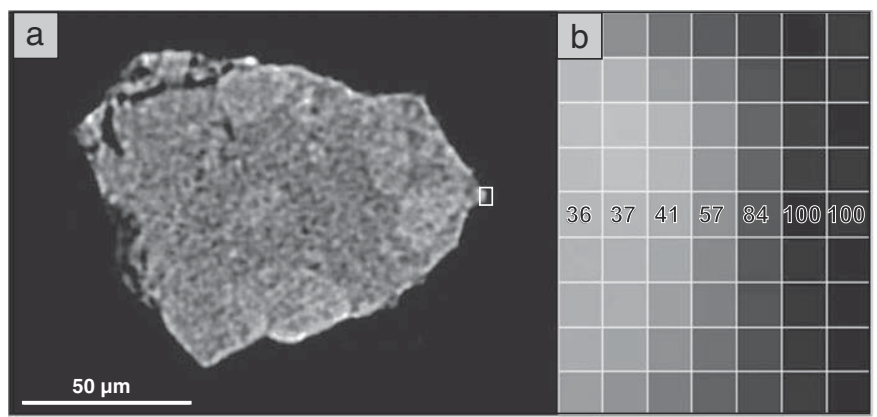

Fig. 4. CT slice of sample MFM03-5 (a). The white rectangle indicates the location of the close-up view shown in (b). Numbers in the central pixel row in (b) are for grayscale tones $(0=$ white, $100=$ black $)$. with a thermionic source, and provided the pixel size is substantially smaller than this value. In the CT slices a resolution of $\sim 1.5 \mu \mathrm{m}$ can be expected if the rotation is accurate and both the electron beam and the sample are stable during scanning. Finally, only objects of $\sim 3.5 \mu \mathrm{m}$ in diameter can be considered as detected and their morphological parameters quantified with reasonable accuracy.

\subsection{Advantages and limitations of SEM micro-CT}

One of the main advantages of SEM micro-CT is its ability to provide full 3D data of the external shape and the interior of ash particles from a single acquisition scan. This is a decisive plus compared to other techniques such as SEM stereo-imaging, which only provides incomplete "surface" information. As already pinpointed by Ersoy et al. (2010), the main drawback of SEM stereo-imaging is that it generates a digital elevation model only for the upper surface of the specimen, while the lower surface is inaccessible to the electron beam and has to be interpolated. Alternatively, the specimen can be flipped upside down to reveal its opposite side and the data of both sides compiled to obtain a volume rendering of the whole sample. This option, however, is very impractical and time-consuming to implement, besides being a potential source of errors in the calculations of morphological parameters. Moreover, because of the non-penetrative nature of electrons, SEM stereo-imaging cannot provide any information on the interior of the sample, such as the amount, size and distribution of the trapped vesicles and microcrystals. Even if this information can be partly obtained by other means, e.g. through the analysis of thin sections from cemented aggregates or measurements of vesicle imprints on the particle surfaces, it remains true that the 3D data derived from SEM stereo-imaging are fragmented and incomplete. SEM stereo-imaging is therefore not an equivalent substitute for SEM micro-CT. Lastly, the association of the full 3D capabilities of SEM micro-CT with the visualization and measurement tools provided by softwares such as Blob3D makes possible the calculation of a wide spectrum of morphological parameters which are not straightforward to quantify otherwise. These include the determination of volumes, maximum and minimum area projections, sphericity, circularity, elongation, flatness and shape factors. The measurements obtained by SEM micro-CT are reliable, provided the system has been calibrated properly (s. Section 3.3). It has been shown by Bagheri et al. (2015) that measurements of linear dimensions are within a 3\% error interval using the optical microscope and the SEM micro-CT technique.

The SEM micro-CT system offers a much better spatial resolution than conventional micro-CT devices $(0.65 \mu \mathrm{m}$ vs $\sim 6 \mu \mathrm{m}$ for the X-ray shadow projections), it is more accessible than the very few synchrotron micro-CT facilities equipped with a full-field X-ray microscope, and it costs about one order of magnitude less than the recently released $\mathrm{X}$-ray nano-CT devices. Moreover, SEM micro-CT enables volumes up to $\sim 0.01 \mathrm{~mm}^{3}$ (for objects with an intermediate X-ray attenuation coefficient) and $\sim 1 \mathrm{~mm}^{3}$ (for objects with a low X-ray attenuation coefficient) to be analyzed. The technique is therefore perfectly suited for the study of the lower fraction of coarse volcanic ash particles $(64-500 \mu \mathrm{m} ; 1-4$ $\varphi$ ). However, the technical constraints that have to be faced to break the usual spatial resolution limit (possible deformation of the Pt/Ir tip due to heating, decrease of the X-ray flux due to the small size of the $\mathrm{X}$-ray emission volume, practical difficulties in manipulating and centering tiny objects on the sample holder, need for a forward projection procedure to compensate for mechanical inaccuracies of the stage) make it hardly applicable to fine ash $(<64 \mu \mathrm{m} ;>4 \varphi)$. Other tomographic techniques on the market, such as atom probe tomography (Kelly and Miller, 2007) and electron tomography (Scott et al., 2012), are better suited to achieve unparalleled spatial resolution (down to $\sim 2.4 \AA$ ), but they are restricted to tiny and needle-shaped objects $\left(<10^{-12} \mathrm{~mm}^{3}\right)$, which are orders of magnitude smaller than most fine ash particles. Great expectations are placed in the recently released X-ray nano-CT devices, but the applicability of those instruments in the study of fine ash remains to be tested and validated. Thus, despite the large panel 
of tomographic methods available nowadays, technical barriers are still to be surmounted to provide a full 3D characterization of fine volcanic ash particles $<64 \mu \mathrm{m}(>4 \varphi)$. This is unfortunate as particles of that size raise most concerns due to their long atmospheric residence time and ability to cause serious respiratory diseases (Horwell and Baxter, 2006) and jet engine damage (Casadevall, 1994).

The time required to acquire high-quality data is an important issue in the use of the SEM micro-CT technique. Acquisition time is mostly related to the optical capabilities of the SEM gun and optics. Ideally, the SEM column should be able to generate the highest possible current intensity (in order to maximize the $\mathrm{X}$-ray flux) without defocussing the electron beam (to guarantee optimal spatial resolution on the metal target). Those analytical conditions cannot be achieved by most SEMs in operation as of yet (including the CamScan MV 2300 SEM used in this study). However, spectacular technical improvements in this field have been developed and patented in recent years (mostly by JEOL Ltd, Tokyo, Japan) to break up this limit. Those advances include the use of an in-lens thermal field-emission gun, in which the emitter is inserted within the first condenser lens to annihilate the initial loss of electrons, and an aperture angle control lens, which provides a realtime control on the aperture angle of the objective lens whatever the current intensity. Those instruments are capable of generating currents up to $1000 \mathrm{nA}$ without significant defocussing. Using such a high current intensity, the acquisition time is reduced by a factor of 10 compared to scans performed at $100 \mathrm{nA}$ (all other settings being the same), making the acquisition of a full SEM micro-CT scan in 1 to $2 \mathrm{~h}$ perfectly realistic. Alternatively, these new capabilities could also be used to improve significantly the signal-to-noise ratio by increasing the number of averaged frames collected to generate the X-ray shadow projections. Thus, the flexibility of the SEM gun and optics is a determinant factor to gain in productivity and/or image quality. The gain in productivity enables a larger number of particles to be analyzed, in order to make the interpretation statistically relevant. Acquiring SEM micro-CT data at high-resolution in standard thermionic SEMs may be time-consuming and only attractive when small sample sets are considered. Using the state-of-the-art generation of FE-SEMs opens the technique to new fields of research for which counting statistics is an issue. In addition, the gain in image quality allows for the segmentation of nearby objects with close X-ray attenuation coefficients, such as olivine or pyroxene microcrystals in a glassy groundmass. Both achievements are clearly unrealistic when a standard SEM is used.

Other limitations of SEM micro-CT include the drawbacks inherent to all CT techniques, such as the possible errors generated by userdefined operations. For example, choices made during thresholding and segmentation may completely change the volume of selected data, as well as the connectivity between adjacent objects such as vesicles. Data smoothing used to remove noise and artifacts may also lead to misinterpretation. Inappropriate smoothing is particularly detrimental to the quantification of different aspects of shape, such as angularity, roundness or surface roughness, as well as to the calculations of parameters such as perimeter or surface area. Therefore, as for any CT work, the quality and accuracy of the data are largely user-dependent, and require a previous knowledge of the material to be analyzed.

\subsection{Conclusions and perspectives}

In this study the capabilities of SEM micro-CT for the 3D analysis of small volcanic ash particles have been presented. Using a standard SEM with a thermionic source and a bulk brass target a resolution of $0.65 \mu \mathrm{m}$ can be expected in the X-ray shadow projections. In complex samples such as volcanic ash particles, features $>20 \mu \mathrm{m}^{3}(\sim 3.5 \mu \mathrm{m}$ in diameter) can be detected and quantified with reasonable accuracy. The technique is particularly suited for studies in which only a small sample set is involved due to the long acquisition and post-processing time. Coupled with the new specially-developed functionalities of the Blob3D software, it provides an inexpensive way to calculate accurately the morphological aspects of shape in small volcanic ash particles and their constituents, including the factors frequently used as input parameters in ash transport and dispersion models.

Productivity and/or data quality could be increased significantly using an in-lens field-emission SEM, whereas spatial resolution could be improved through the use of an X-ray camera with quantum efficiency optimized for the high range of the X-ray spectrum and a sharp highdensity target placed at a very short distance from the sample $(<1 \mathrm{~mm})$. Those latter measures, however, impose stringent technical constraints which make the technique hardly applicable to fine volcanic ash particles $(<64 \mu \mathrm{m} ;>4 \varphi)$.

\section{Acknowledgments}

The authors are very grateful to Laurent Nicod for the preparation of epoxy mounts, and to David Floess for his technical support during micro-CT data treatment. Bart Pauwels is thanked for sharing his skills on SEM micro-CT and for his constructive comments on our data. Sergey Babin from the aBeam Technologies company (Hayward, California, USA) is gratefully acknowledged for the fruitful email correspondence we had with him regarding the measurements of electron probe diameters. Two anonymous reviewers helped to improve the content and clarity of the paper. The present study was financially supported by the University of Lausanne (Switzerland).

\section{Appendix A. Supplementary data}

Supplementary data to this article can be found online

\section{References}

Alfano, F., Bonadonna, C., Delmelle, P., Costantini, L., 2011. Insights on tephra settling velocity from morphological observations. J. Volcanol. Geotherm. Res. 208, 86-98.

Armienti, P., Macedonio, G., Pareschi, M.T., 1988. A numerical model for simulation of tephra transport and deposition: applications to May 18, 1980, Mount St. Helens eruption. J. Geophys. Res. 93, 6463-6476.

Arnold, J.R., Testa, J.P.J., Friedman, P.J., Kambic, G.X., 1983. Computed tomographic analyses of meteorite inclusions. Science 219, 383-384.

Babin, S., Gaevski, M., Joy, D.C., Machin, M., Martynov, A., 2006. Technique to automatically measure electron-beam diameter and astigmatism: BEAMETR. J. Vac. Sci. Technol. 24, 2956-2959.

Bagheri, G.H., Bonadonna, C., Manzella, I., Vonlanthen, P., 2015. On the characterization of size and shape of irregular particles. Powder Technol. 270, 141-153.

Baker, D.R., Mancini, L., Polacci, M., Higgins, M.D., Gualda, G.A.R., Hill, R.J., Rivers, M.L., 2012. An introduction to the application of X-ray microtomography to the threedimensional study of igneous rocks. Lithos 148, 262-276.

Barsotti, S., Neri, A., Scire, J.S., 2008. The VOL-CALPUFF model for atmospheric ash dispersal: 1. approach and physical formulation. J. Geophys. Res. 113, B03208.

Blong, R.J., 1984. Volcanic Hazards. Academic Press, Sydney (424 pp.).

Blott, S.J., Pye, K., 2008. Particle shape: a review and new methods of characterization and classification. Sedimentology 55, 31-63.

Bonadonna, C., Connor, C.B., Houghton, B.F., Connor, L., Byrne, M., Laing, A., Hincks, T., 2005. Probabilistic modeling of tephra dispersion: hazard assessment of a multiphase eruption at Tarawera, New Zealand. J. Geophys. Res. 110, B03203.

Boons, S., 2010. A new volume rendering software: CTVox. SkyScan User Meeting 2010. Mechelen.

Brazier, S., Davis, A.N., Sigurdsson, H., Sparks, R.S.J., 1982. Fallout and deposition of volcanic ash during the 1979 explosive eruption of the Soufriere of St. Vincent. J. Volcanol. Geotherm. Res. 14, 335-359.

Brownlow, L.A., Mayo, S.C., Miller, P.R., Sheffield-Parker, C.J., 2006. Towards 50 nanometre resolution with an SEM-hosted X-ray microscope. Microsc. Anal. 20, 13-15.

Bruyndonckx, P., Sasov, A.Y., Pauwels, B., 2010. Towards sub-100-nm X-ray microscopy for tomographic applications. Powder Diffract. 25, 157-160.

Buettner, R., Dellino, P., Zimanowski, B., 1999. Identifying magma water interaction from the surface features of ash particles. Nature 401, 688-690.

Bursik, M.I., 1989. Effects of the drag force on the rise height of particles in the gas-thrust region of volcanic eruption columns. Geophys. Res. Lett. 16, 441-444.

Carey, S.N., Sigurdsson, H., 1982. Influence of particle aggregation on deposition of distal tephra from the May 18, 1980, eruption of Mount St. Helens Volcano. J. Geophys. Res. 87, 7061-7072.

Carter, A.J., Durant, A.J., Ramsey, M.S., Skilling, I.P., Wolfe, A., 2009. Micron-scale roughness of volcanic surfaces from thermal infrared spectroscopy and scanning electron microscopy. J. Geophys. Res. 114, B02213. 
Casadevall, T.J., 1994. Volcanic ash and aviation safety. Proceedings of the first international symposium on volcanic ash and aviation safety. U.S. Geol. Surv. Bull. 2047 (450 pp.).

Cazaux, J., Erre, D., Mouze, D., Patat, J.M., Rondot, S., Sasov, A.Y., Trebbia, P., Zolfaghari, A., 1993. Recent developments in X-ray projection microscopy and X-ray microtomography applied to materials science. J. Phys. 3, 2099-2104.

Chhabra, R.P., Agarwal, L., Sinha, N.K., 1999. Drag on non-spherical particles: an evaluation of available methods. Powder Technol. 101, 288-295.

Coltelli, M., Miraglia, L., Scollo, S., 2008. Characterization of shape and terminal velocity of tephra particles erupted during the 2002 eruption of Etna volcano, Italy. Bull. Volcanol. 70, 1103-1112.

Conroy, G.C., Vannier, M.W., 1984. Noninvasive three-dimensional computer imaging of matrix-filled fossil skulls using high-resolution computed tomography. Science 226, 456-458.

Cormack, A.M., 1963. Representation of a function by its line integrals, with some radiological applications. J. Appl. Phys. 17, 2722-2727.

Costa, A., Macedonio, G., Folch, A., 2006. A three-dimensional Eulerian model for transport and deposition of volcanic ashes. Earth Planet. Sci. Lett. 241, 634-647.

Degruyter, W., Bachmann, O., Burgisser, A., 2010. Controls on magma permeability in the volcanic conduit during the climactic phase of the Kos Plateau Tuff eruption (Aegean Arc). Bull. Volcanol. 72, 63-74.

Dellino, P., La Volpe, L., 1995. Fragmentation versus transportation mechanisms in the pyroclastic sequence of Monte Pilato-Rocche Rosse (Lipari, Italy). J. Volcanol. Geotherm. Res. 64, 211-231

Dellino, P., La Volpe, L., 1996. Image processing analysis in reconstructing fragmentation and transportation mechanisms of pyroclastic deposits: the case of Monte PilatoRocche Rosse eruptions, Lipari (Aeolian Islands, Italy). J. Volcanol. Geotherm. Res. $71,13-29$.

Dellino, P., Mele, D., Bonasia, R., Braia, G., La Volpe, L., Sulpizio, R., 2005. The analysis of the influence of pumice shape on its terminal velocity. Geophys. Res. Lett. 32, L21306

Dellino, P., Gudmundsson, M.T., Larsen, G., Mele, D., Stevenson, J.A., Thordarson, T. Zimanowski, B., 2012. Ash from the Eyjafjallajökull eruption (Iceland): fragmentation processes and aerodynamic behavior. J. Geophys. Res. 117, B00C04.

Delmelle, P., Lambert, M., Dufrêne, Y., Gerin, P., Oskarsson, N., 2007. Gas/aerosol interaction in volcanic plumes: new insights from surface analyses of fine ash particles. Earth Planet. Sci. Lett. 259, 159-170.

Drouin, D., Couture, A.R., Joly, D., Tastet, X., Aimez, V., Gauvin, R., 2007. CASINO V2.42 - a fast and easy-to-use modeling tool for scanning electron microscopy and microanalysis users. Scanning 29, 92-101.

Eiríksson, J., Sigurgeirsson, M., Hoelstad, T., 1994. Image analysis and morphometry of hydromagmatic and magmatic tephra grains, Reykjanes volcanic system, Iceland. Jökull 44, 41-65.

Ersoy, O., 2007. Analyse morphologique quantitative des cendres des dépôts pyroclastiques d'origine hydrovolcanique et magmatique. Université Blaise Pascal, Clermont-Ferrand (France).

Ersoy, O., 2010. Surface area and volume measurements of volcanic ash particles by SEM stereoscopic imaging. J. Volcanol. Geotherm. Res. 190, 290-296.

Ersoy, O., Şen, E., Aydar, E., Tatar, I., elik, H.H., 2010. Surface area and volume measurements of volcanic ash particles using micro-computed tomography (micro-CT): a comparison with scanning electron microscope (SEM) stereoscopic imaging and geometric considerations. J. Volcanol. Geotherm. Res. 196, 281-286.

Evans, J.R., Huntoon, J.E., Rose, W.I., Varley, N.R., Stevenson, J.A., 2009. Particle sizes of andesitic ash fallout from vertical eruptions and co-pyroclastic flow clouds, Volcán de Colima, Mexico. Geology 37, 935-938.

Feldkamp, L.A., Davis, L.C., Kress, J.W., 1984. Practical cone-beam algorithm. J. Opt. Soc. Am. A 1, 612-619.

Folch, A., 2012. A review of tephra transport and dispersal models: evolution, current status, and future perspectives. J. Volcanol. Geotherm. Res. 235-236, 96-115.

Fubini, B., Zanetti, G., Altilia, S., Tiozzo, R., Lison, D., Saffiotti, U., 1999. Relationship between surface properties and cellular responses to crystalline silica: studies with heat-treated cristobalite. Chem. Res. Toxicol. 12, 737-745.

Ganser, G.H., 1993. A rational approach to drag prediction of spherical and nonspherical particles. Powder Technol. 77, 143-152.

Genareau, K., Proussevitch, A.A., Durant, A.J., Mulukutla, G.K., Sahagian, D.L., 2012. Sizing up the bubbles that produce very fine ash during explosive volcanic eruptions. Geophys. Res. Lett. 39, L15306.

Gilbert, J.S., Lane, S.J., 1994. The origin of accretionary lapilli. Bull. Volcanol. 56, 398-411.

Glaze, L.S., Self, S., 1991. Ashfall dispersal for the 16 September, 1986 eruption of Lascar, Chile, calculated by a turbulent diffusion model. Geophys. Res. Lett. 18, 1237-1240.

Goldstein, J.I., Newbury, D.E., Echlin, P., Joy, D.C., Lyman, C.E., Lifshin, E., Sawyer, L., Michael, J.R., 2007. Scanning Electron Microscopy and X-Ray Microanalysis. Springer Verlag, New York (690 pp.).

Gualda, G.A.R., Rivers, M.L., 2006. Quantitative 3D petrography using X-ray tomography: application to Bishop Tuff pumice clasts. J. Volcanol. Geotherm. Res. 154, 48-62.

Heiken, G., 1972. Morphology and petrology of volcanic ash. Geol. Soc. Am. Bull. 83, 1961-1988.

Herman, G.T., 1979. Correction for beam hardening in computed tomography. Phys. Med. Biol. 24, 81-106.

Hetland, R.B., Schwarze, P.E., Johansen, B.V., Myran, T., Uthus, N., Refsnes, M., 2001. Silicainduced cytokine release from A549 cells: importance of surface area versus size. Hum. Exp. Toxicol. 20, 46-55.

Horwell, C.J., Baxter, P.J., 2006. The respiratory health hazards of volcanic ash: a review for volcanic risk mitigation. Bull. Volcanol. 69, 1-24.

Horwell, C.J., Fenoglio, I., Ragnarsdottir, K.V., Sparks, R.S.J., Fubini, B., 2003. Surface reactivity of volcanic ash from the eruption of Soufrière Hills volcano, Montserrat, West Indies with implications for health hazards. Environ. Res. 93, 202-215.
Hounsfield, G.N., 1973. Computerized transverse axial scanning (tomography): part I. Description of system. Br. J. Radiol. 46, 1016-1022.

Hovington, P., Drouin, D. Gauvin, R, 1997. CASINO: a new Monte Carlo code in Clanguage for electron beam interaction - part I: description of the program. Scanning 19, 1-14.

Hubbell, J.H., Seltzer, S.M., 2007. Tables of X-Ray Mass Attenuation Coefficients and Mass Energy-Absorption Coefficients from $1 \mathrm{keV}$ to $20 \mathrm{MeV}$ for Elements $\mathrm{Z}=1$ to 92 and 48 Additional Substances of Dosimetric Interest. National Institute of Standards and Technology, Gaithersburg.

Hurst, A.W., Turner, R., 1999. Performance of the program ASHFALL for forecasting ashfall during the 1995 and 1996 eruptions of Ruapehu volcano. N. Z. J. Geol. Geophys. 42, 615-622.

Jerram, D.A., Higgins, M.D., 2007. 3D analysis of rock textures: quantifying igneous microstructures. Elem. 3, 239-245.

Kalender, W.A., 2011. Computed Tomography: Fundamentals, System Technology, Image Quality, Applications. John Wiley \& Sons, Hamburg (372 pp.).

Kelly, T.F., Miller, M.K., 2007. Atom probe tomography. Rev. Sci. Instrum. 78, 1-20.

Ketcham, R.A., 2005. Computational methods for quantitative analysis of threedimensional features in geological specimens. Geosphere 1, 32-41.

Ketcham, R.A., Carlson, W.D., 2001. Acquisition, optimization and interpretation of X-ray computed tomographic imagery: applications to the geosciences. Comput. Geosci. $27,381-400$

Ketcham, R.A., Hildebrandt, J., 2014. Characterizing, measuring, and utilizing the resolution of CT imagery for improved quantification of fine-scale features. Nuclear Physics B Proceedings Supplement (??:?-?)

Kiely, C., Sahagian, D.L., Claves, S.R., Misiolek, W.Z., Kiely, C.J., 2007. X-ray ultramicroscopy within an XL30 environmental SEM. Microsc. Microanal. 13, 1576-1577.

Kiely, C., Greenberg, G., Kiely, C.J., 2011. A new look at lunar soil collected from the Sea of Tranquility during the Apollo 11 mission. Microsc. Microanal. 17, 34-48.

Krotkov, N.A., Flittner, D.E., Krueger, A.J., Kostinski, A., Riley, C., Rose, W.I., Torres, O., 1999. Effect of particle non-sphericity on satellite monitoring of drifting volcanic ash clouds. J. Quant. Spectrosc. Radiat. Transf. 63, 613-630.

Liu, X., Sasov, A., 2005. Cluster reconstruction strategies for microCT/nanoCTscanners. Proceedings of Fully 3D Image Reconstruction Meeting in Radiology and Nuclear Medicine, Salt Lake City (USA).

Macedonio, G., Costa, A., Longo, A., 2005. A computer model for volcanic ash fallout and assessment of subsequent hazard. Comput. Geosci. 31, 837-845.

Manga, M., Patel, A., Dufek, J., 2011. Rounding of pumice clasts during transport: field measurements and laboratory studies. Bull. Volcanol. 73, 321-333.

Maria, A., Carey, S.N., 2002. Using fractal analysis to quantitatively characterize the shapes of volcanic particles. J. Volcanol. Geotherm. Res. 107, 2283-2299.

Maria, A., Carey, S.N., 2007. Quantitative discrimination of magma fragmentation and pyroclastic transport processes using the fractal spectrum technique. J. Volcanol. Geotherm. Res. 161, 234-246.

Mayo, S.C., Davis, T.J., Gureyev, T.E., Miller, P.R., Paganin, D., Pogany, A., Stevenson, A.W., Wilkins, S.W., 2003. X-ray phase-contrast microscopy and microtomography. Opt. Express 11, 2289-2302.

Mele, D., Dellino, P., Sulpizio, R., Braia, G., 2011. A systematic investigation on the aerodynamics of ash particles. J. Volcanol. Geotherm. Res. 203, 1-11.

Mills, O.P., Rose, W.I., 2010. Shape and surface area measurements using scanning electron microscope stereo-pair images of volcanic ash particles. Geosphere 6, 805-811.

Mitchell, D.L., 1996. Use of mass- and area-dimensional power laws for determining precipitation particle terminal velocities. J. Atmos. Sci. 53, 1710-1723.

Morrissey, M.M., Zimanowski, B., Wohletz, K.H., Buettner, R., 2000. Phreatomagmatic fragmentation. In: Sigurdsson, H., Houghton, B.F., McNutt, S.R., Rymer, H., Stix, J. (Eds.), Encyclopedia of Volcanoes. Academic Press, London, pp. 431-445.

Natterer, F., Wübbeling, F., 2001. Mathematical Methods in Image Reconstruction, Philadelphia (223 pp.)

New, P.F.J., Scott, W.R., Schnur, J.A., Davis, K.R., Traveras, J.M., 1974 Computerized axial tomography with EMI scanner. Radiology 110, 109-123.

Pauwels, B., Liu, X., Sasov, A.Y., 2010. X-ray nanotomography in an SEM. In: Stock, S.R. (Ed.), Developments in X-Ray Tomography VII. Proceedings of the SPIE 7804, San Diego (USA).

Polacci, M., Baker, D.R., Mancini, L., Tromba, G., Zanini, F., 2006. Three-dimensional investigation of volcanic textures by X-ray microtomography and implications for conduit processes. Geophys. Res. Lett. 33, L13312.

Proussevitch, A.A., Ketcham, R.A., Carlson, W.D., Sahagian, D.L., 1998. Preliminary results of X-ray CT analysis of Hawaiian vesicular basalts. Eos 79, 360.

Proussevitch, A.A., Mulukutla, G.K., Sahagian, D.L., 2011. A new 3D method of measuring bubble size distribution from vesicle fragments preserved on surfaces of volcanic ash particles. Geosphere 7, 62-69.

Pruppacher, H.R., Klett, J.D., 1997. Microphysics of Clouds and Precipitation. Kluwer Academic Publishers, Dordrecht (955 pp.).

Radon, J., 1917. Über die Bestimmung von Funktionen durch ihre Integralwerte längs gewisser Mannigfaltigkeiten. Berichte über die Verhandlungen der Königlich sächsische Akademie der Wissenschaften zu Leipzig 69, 262-277.

Rau, C., Crecea, V., Liu, W., Richter, C.P., Petersen, K.M., Jemian, P.R., Neuhäusler, U., Schneider, G., Yu, X., Braun, P.V., Chiang, T.C., Robinson, I.K., 2007. Synchrotronbased imaging and tomography with hard X-rays. Nucl. Instrum. Methods Phys. Res. 261, 850-854.

Rausch, J., Grobéty, B., Vonlanthen, P., 2015. Eifel maars: quantitative shape characterization of juvenile ash particles (Eifel Volcanic Field, Germany). J. Volcanol. Geotherm. Res. 291, 86-100

Riley, C.M., Rose, W.I., Bluth, G.J.S., 2003. Quantitative shape measurements of distal volcanic ash. J. Geophys. Res. 108, 2504

Rose, W.I., 1977. Scavenging of volcanic aerosol by ash - atmospheric and volcanologic implications. Geology 5, 621-624. 
Sasov, A.Y., 1985. Computerized microtomography in scanning electron microscopy. Scanning Electron Microscopy: 1109-1120.

Sasov, A.Y., 2008. Non-destructive 3D imaging of the objects internal microstructure by microCT attachment for SEM. 14th European Microscopy Congress. Springer, Aachen (Germany), pp. 619-620.

Sasov, A.Y., Liu, X., Salmon, P.L., 2008. Compensation of mechanical inaccuracies in microCT and nano-CT. In: Stock, S.R. (Ed.), Developments in X-Ray Tomography VI. Proceedings of the SPIE 7078, San Diego (USA).

Sasov, A.Y., Bruyndonckx, P., Pauwels, B., Liu, X., 2010a. Breaking the resolution limit: laboratory X-ray system with $50 \mathrm{~nm}$ imaging resolution and 3D capabilities. Imaging Microsc. 12, 18-20.

Sasov, A.Y., Pauwels, B., Bruyndonckx, P., 2010b. New type of lensless X-ray source for laboratory nano-CT with $50 \mathrm{~nm}$ resolution. Developments in X-Ray Tomography VIIProceedings of the SPIE 7804, San Diego (USA).

Schwaiger, H., Denlinger, R., Mastin, L.G., 2012. Ash3d: a finite-volume, conservative numerical model for ash transport and tephra deposition. J. Geophys. Res. 117 B04204.

Scollo, S., Folch, A., Costa, A., 2008. A parametric and comparative study of different tephra fallout models. J. Volcanol. Geotherm. Res. 176, 199-211.

Scott, M.C., Chen, C.C., Mecklenburg, M., Zhu, C., Xu, R., Ercius, P., Dahmen, U., Regan, B.C., Miao, J., 2012. Electron tomography at 2.4 angström resolution. Nature $483,444-448$.

Shea, T., Houghton, B.F., Gurioli, L., Cashman, K.V., Hammer, J.E., Hobden, B.J., 2010. Textural studies of vesicles in volcanic rocks: an integrated methodology. J. Volcanol. Geotherm. Res. 190, 271-289.

Shin, H., Lindquist, W.B., Sahagian, D.L., Song, S.R., 2005. Analysis of the vesicular structure of basalts. Comput. Geosci. 31, 473-487.

Song, S.R., Jones, K.W., Lindquist, W.B., Dowd, B.A., Sahagian, D.L., 2001. Synchrotron X-ray computed microtomography: studies on vesiculated basaltic rocks. Bull. Volcanol. 63, 252-263.

Sorem, R.K., 1982. Volcanic ash clusters: tephra rafts and scavengers. J. Volcanol. Geotherm. Res. 13, 63-71.

Sparks, R.S.J., Bursik, M.I., Ablay, G.J., Thomas, R.M.E., Carey, S.N., 1992. Sedimentation of tephra by volcanic plumes. Part 2: controls on thickness and grain-size variations of tephra fall deposits. Bull. Volcanol. 54, 685-695.

Sparks, R.S.J., Bursik, M.I., Carey, S.N., Gilbert, J.S., Glaze, L.S., Sigurdsson, H., Woods, A.W., 1997. Volcanic Plumes. Wiley, Chichester (574 pp.).
Stachowiak, G.W., 2000. Particle angularity and its relationship to abrasive and erosive wear. Wear 241, 214-219.

Stringham, G.E., Simons, D.B., Guy, H.P., 1969. The behavior of large particles falling in quiescent liquids. US Geol. Surv. Prof. Pap. 562-C, 1-36.

Suzuki, T., 1983. A theoretical model for dispersion of tephra. In: Shimozuru, D., Yokoyama, I. (Eds.), Arc Volcanism: Physics and Tectonics. Terra Scientific Publishing Company, Tokyo, pp. 95-113.

Tran, C.L., Buchanan, D., Cullen, R.T., Searl, A., Jones, A.D., Donaldson, K., 2000. Inhalation of poorly soluble particles. II. Influence of particle surface area on inflammation and clearance. Inhal. Toxicol. 12, 1113-1126.

Varekamp, J.C., Luhr, J.F., Prestegaard, K.L., 1984. The 1982 eruptions of El Chichón Volcano (Chiapas, Mexico), character of the eruptions, ash-fall deposits, and gas phase. J. Volcanol. Geotherm. Res. 23, 39-68.

Voltolini, M., Zandomeneghi, D., Mancini, L., Polacci, M., 2011. Texture analysis of volcanic rock samples: quantitative study of crystals and vesicles shape preferred orientation from X-ray microtomography data. J. Volcanol. Geotherm. Res. 202, 83-95.

Wen, S., Rose, W.I., 1994. Retrieval of particle sizes and masses in volcanic clouds using AVHRR bands 4 and 5. J. Geophys. Res. 99, 5421-5431.

Wilkins, S.W., Gureyev, T.E., Gao, D., Pogany, A., Stevenson, A.W., 1996. Phase-contrast imaging using polychromatic hard X-rays. Nature 384, 335-338.

Wilson, L., Huang, T.C., 1979. The influence of shape on the atmospheric settling velocity of volcanic ash particles. Earth Planet. Sci. Lett. 44, 311-324.

Witham, C.S., Oppenheimer, C., Horwell, C.J., 2005. Volcanic ash-leachates: a review and recommendations for sampling methods. J. Volcanol. Geotherm. Res. 141, 299-326.

Wohletz, K.H., 1983. Mechanisms of hydrovolcanic pyroclast formation: grain-size, scanning electron microscopy, and experimental studies. J. Volcanol. Geotherm. Res. 17, 31-63.

Zandomeneghi, D., Voltolini, M., Mancini, L., Brun, F., Dreossi, D., Polacci, M., 2010. Quantitative analysis of X-ray microtomography images of geomaterials: application to volcanic rocks. Geosphere 6, 793-804.

Zimanowski, B., Buettner, R., Lorenz, V., Haefele, H.G., 1997. Fragmentation of basaltic melt in the course of explosive volcanism. J. Geophys. Res. 102, 803-814. 